\title{
Prediction of the Aerodynamic Behaviour of a Full-Scale Naval Ship in Head Waves using Detached Eddy Simulation
}

\author{
Ahmed Nisham ${ }^{1}$, Momchil Terziev²*, Tahsin Tezdogan ${ }^{1}$, Thomas Beard ${ }^{3}$, Atilla Incecik ${ }^{2}$
}

${ }^{1}$ Department of Naval Architecture, Ocean and Marine Engineering, University of Strathclyde, Glasgow, UK

${ }^{2}$ Faculty of Engineering, University of Strathclyde, Glasgow, UK

${ }^{3} B M T$, Glasgow, UK

${ }^{*}$ Corresponding author: momchil.terziev@strath.ac.uk 


\begin{abstract}
The airwake behaviour around a ship provides useful information for the safe operation of helicopters on naval ships as well as in helicopter pilot training. This study investigates the impact of ship motions on the airwake behind the superstructure of a naval ship using Detached Eddy Simulation. A full-scale simplified frigate geometry is analysed stationary and in head waves at three different wavelengths under a uniform wind field and in the presence of an atmospheric boundary layer. The results reveal that an atmospheric boundary layer impacts significantly the airwake, as well as the vertical wave-induced motions of the ship, which reduce in amplitude by between $20.9 \%$ and $22.39 \%$ in heave, and up to approximately $38 \%$ in pitch. Moreover, the results show that the presence of an atmospheric boundary layer impacts the ship's heave and pitch motion periods. The flow field is also significantly altered depending on the ambient wavelength and period of motion, particularly in the case where an atmospheric boundary layer is modelled.
\end{abstract}

Keywords: ship airwake; ship aerohydrodynamics; unsteady airwake; ship motions; atmospheric boundary layer; DES

\title{
Nomenclature
}

\begin{tabular}{|c|c|c|c|}
\hline $\begin{array}{l}\overline{u_{\imath}} \\
\overline{\boldsymbol{\tau}}_{i j}\end{array}$ & $\begin{array}{l}\text { Averaged velocity } \\
\text { Mean viscous stress }\end{array}$ & LCB & $\begin{array}{l}\text { Longitudinal centre of } \\
\text { buoyancy }\end{array}$ \\
\hline$f_{\text {ext }}$ & Extrapolated solution & LCF & Longitudinal centre of gravity \\
\hline$T_{e}$ & Encounter period & LES & Large Eddy Simulation \\
\hline $\boldsymbol{U}_{\boldsymbol{C}}$ & Combined uncertainty & $p$ & Order of accuracy \\
\hline $\boldsymbol{V}_{\infty}$ & Free stream velocity & RANS & Reynold Averaged Navier- \\
\hline$f_{e}$ & Encounter frequency & & Stokes \\
\hline \multirow[t]{2}{*}{$f_{1,2,3}$} & Fine, medium and coarse & $\operatorname{Re}$ & Reynolds number \\
\hline & solution & $S$ & Ship wetted area \\
\hline$r_{21}, r_{32}, r$ & Refinement factor & SFS & Simple Frigate Ship \\
\hline $\mathrm{ABL}$ & Atmospheric Boundary Layer & $\mathbf{T}$ & Design draught \\
\hline B & Beam at waterline & $\mathbf{U}$ & Ship speed \\
\hline Св & Block coefficient & URANS & Unsteady Reynolds Averaged \\
\hline \multirow[t]{2}{*}{ CFD } & Computational Fluid & & Navier-Stokes \\
\hline & Dynamics & VoF & Volume of Fluid \\
\hline D & Depth & $\Delta$ & Displacement \\
\hline DES & Detached Eddy Simulation & $\Delta t$ & Time-step \\
\hline EFD & Experimental Fluid Dynamics & $\lambda$ & Wavelength \\
\hline$g$ & Gravitational acceleration & $\rho$ & Density \\
\hline GCI & Grid Convergence Index & $\rho \overline{u^{\prime}{ }_{\imath} u_{J}^{\prime}}$ & Reynolds stress \\
\hline $\mathbf{G M}_{\mathrm{t}}$ & Metacentric height & & \\
\hline $\mathbf{h}$ & $\begin{array}{l}\text { Height above the mean } \\
\text { waterline }\end{array}$ & & \\
\hline KG & Vertical centre of gravity & & \\
\hline $\mathbf{L}$ & $\begin{array}{l}\text { Length between } \\
\text { perpendiculars }\end{array}$ & & \\
\hline
\end{tabular}




\section{Introduction}

A ship in service interacts with the surrounding environment in a variety of ways. Typically, of primary concern are ship responses due to waves, and the danger these pose to the safety of life and cargo. However, a ship does not interact with its environment in a purely passive way. The presence of the hull causes a variety of disturbances to the surrounding media. These include the generation of waves, noise, as well as a disturbed region of air downstream, to mention but a few. Although most studies rightly focus their attention on the hydrodynamic aspects of ship operation, an examination of the disturbed airwake is also of importance. That is particularly the case when launch and recovery operations are conducted on ships from helicopters.

The airwake behind a naval ship has a great impact on the pilot workload of an air vehicle, such as a helicopter, conducting launch and recovery on the helideck of a vessel. The design of a ship's superstructure significantly changes the nature of the airwake (Forrest et al., 2016) . In addition to this, the airwake is further altered by the effects of ship motions, waves, the presence of an Atmospheric Boundary Layer (ABL), and prevailing wind speed and direction. All these effects create large spatial and temporal velocity gradients over the helideck, which for a naval vessel is usually situated on the aft side of the hangar/superstructure.

The flow field of the helicopter operating in this region creates an induced flow field which interacts with the airwake, hence modifying the aerodynamics of the ship. Due to the aforementioned factors, the nature of the airwake limits ship-helicopter operations to a great extent. The large spatial and temporal velocity gradients over the helideck in all three dimensions can be different from the freestream velocity of wind over the sea. Fluctuations in the flow velocity within the range $0.2-2 \mathrm{~Hz}$ impact the workload of the pilot operating launch and recovery of helicopters over the helideck (McRuer, 1994).

Several studies have been conducted to investigate the airwake of a naval ships. Earlier experimental techniques have been used to study the flow field behaviour of model scale ships in wind tunnels using smoke visualisation and anemometry testing (Hurst and Newman, 1988). With the advancement of computational power, Computational Fluid Dynamics (CFD) has been used to predict the features of the airwake. Up to date, the reliability of several CFD techniques in simulating ship airwake has been tested by several researchers (Cao et al., 2016; Dooley et al., 2020; Forrest and Owen, 2010; Liu et al., 1998; Polsky, 2002; Polsky and Bruner, 2002; Reddy et al., 2000; Syms, 2008; Tai and Carico, 1995; Zhang et al., 2018). The adopted methods, techniques, and brief results of these studies are presented in Section 2. It is important to note that most of these studies did not consider the possible effect of ship motions on the airwake, which forms the core of the present study.

The Simple Frigate Shape 2 (SFS2) geometry has been used by the international research community over the past 20 years as a standard ship geometry to assess and compare the airwake results. There 
has been no study conducted on SFS2 to analyse the airwake around the geometry during motion induced by waves. In this study, the airwake behind a modified Simple Frigate Shape (SFS2) was investigated stationary and in waves using CFD. The ship was simulated subjected to three different wavelengths, specifically, $\lambda / L=0.9, \lambda / L=1$, and $\lambda / L=1.2$ in head waves. In order to compare the results, the ship was also modelled stationary to compare against experimental data. The ship was studied under the abovementioned conditions at full-scale only to avoid the possibility of incurring scale effects. All cases were modelled using a uniform wind field, and in the presence of an atmospheric boundary layer to determine its impact on the solution.

The main objective of this work is to investigate the effects of regular head waves on the airwake of a ship. The effects of atmospheric boundary layer are also modelled for a stationary ship and a ship subjected to waves of varying wavelength to determine its influence.

This work is organised as follows. In Section 2, the necessary background is given on both experimental and numerical techniques. This is followed by the methodology, given in Section 3, which includes the case studies and numerical modelling approach. Section 4 contains the results and their discussion, which Section 5 is devoted to conclusions and recommendations for future work.

\section{Background}

The effectiveness of the helicopter-ship operation greatly relies on the ability of the helicopter to launch and recover in various environmental conditions. This ability is based on the helicopter pilot workload which is directly impacted by the behaviour of the airwake behind the superstructure. Therefore, identifying the airwake behaviour at the design stage, and acquiring accurate airwake velocity data to be used in pilot training simulators are two vital factors for improving the effectiveness of these operations (Roper et al., 2006).

The workload on a helicopter pilot is determined based on on-site test trials called First of Class Flight Trials (FOCFTs) conducted after the vessel has been launched. During the trials, pilots fly at as many Wind Over Deck (WOD) angles, depicted in Figure 1, angles and speeds as possible to determine the intensity of the workload. Based on this, experienced pilots determine whether the workload is acceptable for repeated operations (Kääriä, 2012). For each combination of helicopter type and ship and for day and night conditions a separate Ship-Helicopter Operating Limits (SHOLs) will be generated. The SHOLs represent safe relative wind direction and speed combinations for helicopter-ship operations. Implementing modifications to the ship superstructure 
should the pilot workload be too great at the sea trial stage is not possible. This mandates the accurate flow description at the design stage to avoid the above scenario.

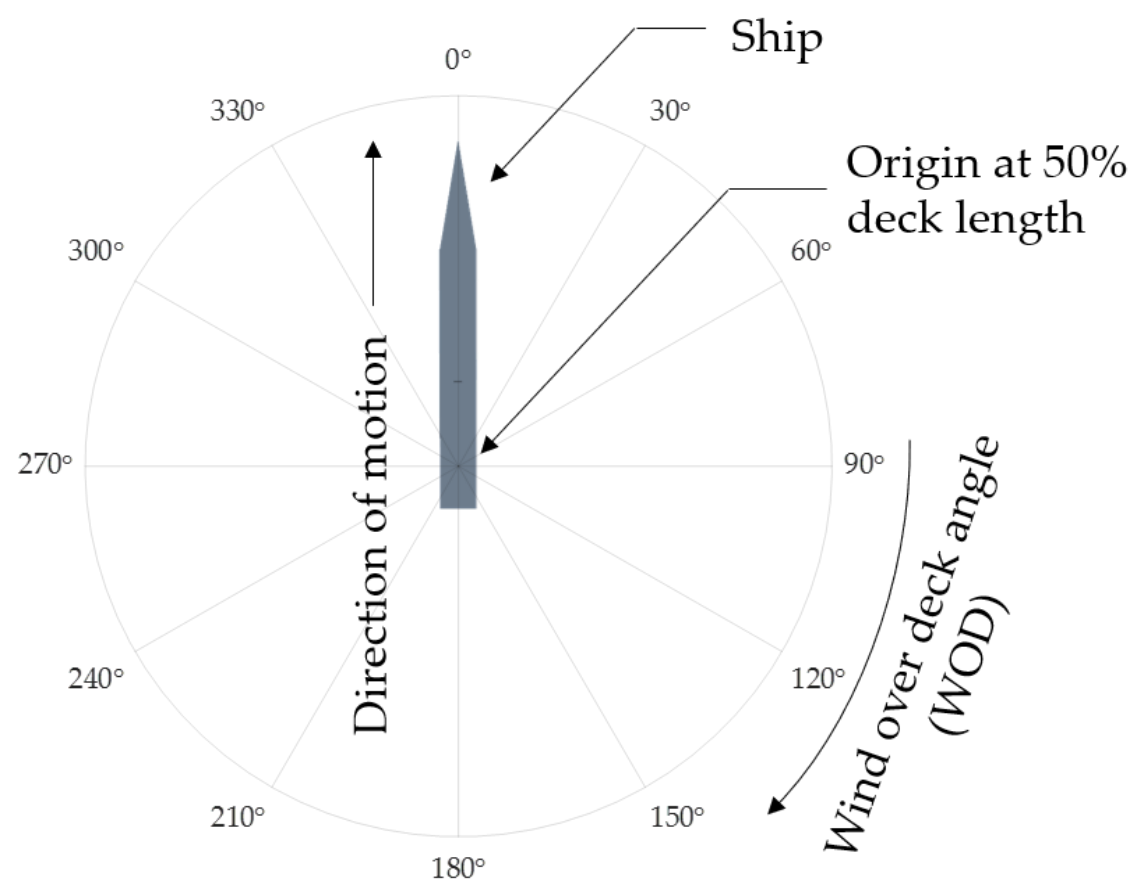

Figure 1. Wind over deck angle definition. The origin is placed at $50 \%$ deck length aft of the hanger of a simplified ship as an indication of where a helicopter may land.

The use of Computational Fluid Dynamics (CFD) to analyse ship airwakes started in the early 1990s. Improvements in the numerical algorithm schemes and with ever-increasing computational power made the simulation of complex flow feasible. One of the earliest studies on the topic using CFD was conducted by Tai and Carico (1995). They simulated the airwake behind a naval ship (DD-963 type destroyer) using a Reynolds Averaged Navier-Stokes (RANS) solver. The analysis was conducted for a stationary ship in the presence of an atmospheric boundary layer at 30 degree WOD angle increments. The results were in good agreement with that of the experimental anemometric measurements obtained by Healey (1992). Similar flow separation at sharp edges such as the edge of the hanger was observed.

Landsberg et al. (1995) studied the flow characteristics of the US Navy destroyer DDG-51, using the unsteady time-averaged flow solver, FAST3D. The flow behaviour with and without the coupled interaction of the helicopter flow was simulated. The time-averaged velocity fluctuations and corresponding frequency analysis showed significant unsteadiness within the range below $1 \mathrm{~Hz}$ in the flow velocity fluctuations over the flight deck. The inclusion of the helicopter downwash in the 
simulation showed an increase by two orders of magnitude of the Power Spectral Density (PSD) over the flight deck within the above-mentioned frequency range.

Liu et al. (1998) studied the flow over the flight deck of the generic frigate ship, also known as Simple Frigate Ship (SFS) using the CFL3D code to compute the flow-field and Non-Linear Disturbance Equation (NLDE) solver to calculate the unsteady components. A key aim of the study was also to compare both solvers. Two major flow separations were observed in their study: one due to the sharp edges, and the other due viscosity. The authors concluded that the former is purely inviscid and independent of the Reynolds number (Re). However, they stated that the flow separation due to viscosity was highly influenced by the Reynolds number.

The flow features predicted by Liu et al. (1998) were found to be in good agreement with the experimental results of Cheney and Zan (1999). Similar to previous studies a flow circulation or vortex behind the hanger was observed where the flow speed is relatively low. Aft of this vortex lies the flow reattachment point where the flow from the sides and over the hanger attaches on the deck. The re-attachment point of their study did not match well with that of the experimental test. The authors suspected this is due to the use of the inviscid approach.

A similar study conducted by Reddy et al. (2000) using the same approach but improved techniques, was found to perform better than the study of Liu et al. (1998). Specifically, in capturing two vortices in the region close to the hanger at $0^{\circ}$ WOD angle. The calculated flow pattern compared well with the experimental results of Cheney and Zan (1999), however, the size of the flow recirculation points and vortices were found to be different. The authors presumed this might be due to viscous flow effects, grid sizing, geometry, and turbulence model. In their study, Reddy et al. (2000) used SFS geometry with flow directions at $0^{\circ}, 45^{\circ}$ and $90^{\circ}$ WOD angles. The relative wind speed was taken as $\mathrm{V}=70 \mathrm{ft} / \mathrm{s}$ (approximately 43 knots). The simulation was meshed with a structured grid and the flow was computed using the $k-\varepsilon$ turbulence model (where $k$ is the turbulent kinetic energy and $\varepsilon$ is the dissipation rate) in commercial CFD code FLUENT.

A series of studies performed by Polsky $(2006,2003,2002)$ contributed to a significant improvement in the area of understanding ship airwakes using CFD (Polsky et al., 2007; Polsky and Ghee, 2004, 2008). Throughout these studies, several CFD techniques were tested and compared. Polsky (2002) questioned the accuracy of the unsteady airwake features performed at model scales such as 1/100 using a wind tunnel. According to the abovementioned work, the suitable conditions for a full-scale ship could not be attained in a wind tunnel with a model-scale of this size. Therefore, the unsteady features which are critical to pilot workload could not be captured well. It was also argued that a full-scale CFD simulation can be a better option to obtain time-accurate data. 
Polsky and Bruner (2000) and Polsky (2002) predicted the flow field behind the superstructure of an LHA-class U.S. Navy ship using Monotone Integrated Large-Eddy Simulation (MILES) (Boris et al., 1992) with $k-\omega$ turbulence model (where $\omega$ is the dissipation frequency). Another purpose of the study was to test the applicability of the solver models to study ship airwakes. The simulations were conducted using full-scale geometry with the unstructured Navier-Stokes solver, Cobalt (Strang et al., 1999). The results were compared with wind tunnel data from NASA Ames Fluid Mechanics Lab and full-scale data obtained at sea. The time-accurate, averaged data were found to be in good agreement with experimental measurements. However, the steady-state results did not match well. Polsky (2002) also concluded that the flow was Reynolds number independent at approximately $\operatorname{Re}=10^{5} \sim 3 \times 10^{5}$ range.

Polsky (2003) further investigated the flow field of the geometry SFS and LHA-Class ship using ABL velocity profile. The same techniques as those used in the studies of Polsky and Bruner (2000) and Polsky (2002) were used in Polsky (2003), however, the wind direction at $90^{\circ}$ angle was focused on. The inclusion of ABL generally improved the overall results obtained from this simulation compared with the experimental data.

Woodson and Ghee (2005) computed the flow field behind a DDG-51 Flight II-A class destroyer using time-accurate CFD solver with MILES (Boris et al., 1992). The Cobalt CFD code was used for the computation. Wind angles of $0^{\circ}$ and $10^{\circ}$ were analysed in their study. The results were compared with experimental data of the $1 / 144^{\text {th }}$ model-scale of a USS Winston S. Churchill (DDG-81), tested in a subsonic wind tunnel. It was found that the results were in good agreement with the experimental data. The study aimed to prove that CFD methods were suitable to provide accurate airflow data to populate the pilot training helicopter simulators than the data being used in the ground-based simulators of the time.

A study conducted by Roper et al. (2006) was, to the best of the authors' knowledge, the first study in which the airwake around the stationary SFS2 geometry was analysed using the CFD approach. A steady-state approach with the $k-\omega$ turbulence model was used to simulate the flow at a speed of 40 knots using the commercial software Fluent. The study aimed to produce a database of airwake measurements to implement in the flight simulation environment. However, after pilot testing, the authors identified that the simplification of the geometry, the stationary model and lack unsteadiness in the airwake had resulted in a lower workload on pilots than normally experienced. In the study conducted by Syms (2008), a Simple Frigate Ship 2 (SFS2) geometry was used. The flow around both SFS1 and SFS2 geometries with helicopter rotor interaction was simulated using the time-accurate unsteady lattice-Boltzmann (LBM) flow solver, PowerFLOW. The Root Mean Square (RMS) of the velocity fluctuations of the simulation was compared with experimental data. It was 
observed that the dominant flow features of the airwake, such as the vortices, were captured well in the simulation. However, the computed flow field contains less dissipation of turbulent kinetic energy than wind tunnel experiments. The mean velocity gradients showed in the simulations were also slightly higher than the experimental results. Nevertheless, the authors concluded that PowerFLOW is suitable to predict the flow topology around a frigate like a ship. It should also be mentioned that the experimental data for SFS1 and SFS2 geometries used in the study of Syms (2008) were both obtained from National Research Council Canada (NRC) (Cheney and Zan, 1999).

Forrest and Owen (2010) investigated the airwake over the flight deck of an SFS2 and a Royal Navy Type 23 Frigate (T23) ship. The geometries were assessed using Detached-Eddy-Simulation (DES) in an unstructured grid. Three WOD angles were simulated and the mean velocity components were measured at specific locations over the ship geometry. The results of the T23 geometry investigated in their study were compared with full-scale measurements obtained at sea. Additionally, including an ABL was observed to have significantly improved the results.

In a study performed by Cao et al. (2016), the effectiveness of CFD methods, Reynold Averaged Navier-Stokes (RANS) and Detached Eddy Simulation (DES) in investigating ship airwake was explored. The authors recorded the flow components at locations over the flight deck similar to that of Forrest and Owen (2010). Results using both CFD methods were compared with the NRC experimental data (Cheney and Zan, 1999). While the velocity components obtained via a RANS method in headwind case did not match well with experimental data, similar results obtained using DES matched well. Therefore, the authors concluded that the DES method is suitable to predict flow field over the flight deck accurately. It was also observed that the flow reattaches approximately $3 \times h$ distance aft of the aft face of the hanger, where $h$ is the hanger height.

The study of Zhang et al. (2018) compared the ability of further CFD methods to accurately predict the airwake behind an SFS2 geometry. In their study, Partially Averaged Navier-Stokes (PANS) and Large Eddy Simulation (LES) were compared. The results of the abovementioned study were compared with the test data from NRC (Cheney and Zan, 1999). The authors observed that PANS, with a finer grid, captured the small-scale instantaneous flow features very well, while both methods captured the large flow separations accurately. However, when tested with a coarse grid, PANS behaved similarly to Unsteady Reynolds Averaged Navier-Stokes (URANS) method.

In a review of aerodynamic modelling and simulation of the dynamic interface by Zan (2005) it was concluded that the effect of rolling motion on the airwake is not a serious concern. However, the recent study Dooley et al. (2020) suggested otherwise. In their study, the authors analysed the effects of ship motion and waves on the airwake behaviour over the ONRT geometry. ONRT geometry, also known as DTMB model 5613 was a model of the U.S Navy Zumwalt class destroyer DDG-1000. 
Regular head waves with wavelengths $\lambda=1.2 \mathrm{~L}$ and 1.55L (where the $\mathrm{L}$ is the ship length between perpendiculars) were modelled with wind speeds of 15 knots and 35 knots. The ship speed was kept constant at 15 knots throughout. A baseline case of no motion and no waves were simulated to compare the results with that of the motion. Dooley et al. (2020) stated that the effects of ship motion can be neglected for low motion cases such as for sea state 3.

Based on the literature survey conducted above, it may be concluded that the effects of wave induced motions on the airwake can be considered a gap in the current understanding. This study presents an attempt to address the identified gap by modelling the airwake of a ship stationary and in waves with and without an atmospheric boundary layer, taking into account the wave induced motions.

\section{Methodology}

This section gives a brief description of the methodology adopted to model the problem at hand. The stationary cases, cases in head waves, as well as those featuring an atmospheric boundary layer are discussed jointly.

All numerical simulations were split into major scenarios as listed in Table 1. In the first scenario, the ship was kept at rest and wind at a speed of $25.812 \mathrm{~m} / \mathrm{s}$ was applied. In the second scenario, in addition to the wind, the ship was given a forward speed of $12.358 \mathrm{~m} / \mathrm{s}$ (Froude number, Fr=0.335) in the head seas direction. In this second scenario, the ship in head waves was simulated with three different wavelengths. The resulting wind speed, listed in Table 1 corresponds to the sum of the ship speed and the wind speed. In both the stationary simulations and the simulations in waves, the ship is subjected to the same wind condition, but in the simulations in waves this results due to the ship's motion into the wind. In practice, the numerical simulations where an atmospheric boundary layer is not modelled feature the same inlet velocity $(25.812 \mathrm{~m} / \mathrm{s})$.

Several studies conducted on simulating ship motions have used similar speeds (Carrica et al., 2007; Tezdogan et al., 2015). For all wave conditions, the wave steepness was taken to be $1 / 60$ of the wavelength following Simonsen et al. (2013). The wave encounter frequency, $f_{e}$ was calculated using Eq. (1):

$f e=\sqrt{\frac{g}{2 \pi \lambda}}+V / \lambda$

where $\mathrm{g}$ is the gravitational acceleration, $\mathrm{V}$ is the ship's forward speed, and $\lambda$ is the wavelength.

The Atmospheric Boundary Layer along the sea surface was modelled using the $1 / 7^{\text {th }}$ power law, following Rosenfeld et al. (2015): 


$$
V(h)=V_{\text {ref }} \times\left(h / h_{\text {ref }}\right)^{1 / 7}
$$

where $V(h)$ is the wind velocity at any given height, $h$ from the sea surface. $V_{\text {ref }}$ is the reference velocity, which is equal to the free stream velocity of the simulations without the ABL, while $h_{r e f}$ is the height of the highest point on the ship funnel from the sea surface $(16.764 \mathrm{~m})$. As stated previously, all cases given in Table 1 were repeated in the presence of an atmospheric boundary layer. The inclusion of an ABL is important since it is typically present over all surfaces (including the sea surface), and is therefore a necessary ingredient to make numerical simulations physically consistent.

Table 1. Test matrix (note that all conditions are repeated in the presence of an ABL).

\begin{tabular}{|c|c|c|c|c|c|c|c|c|}
\hline Scenario & Identifier & $\begin{array}{l}\text { Wind } \\
\text { speed, } \\
(\mathrm{m} / \mathrm{s})\end{array}$ & $\begin{array}{l}\text { Ship } \\
\text { speed, } \\
(\mathrm{m} / \mathrm{s})\end{array}$ & $\begin{array}{l}\text { Resulting } \\
\text { speed } \\
(\mathrm{m} / \mathrm{s})\end{array}$ & $\begin{array}{l}\text { Wave } \\
\text { height } \\
\text { (m) }\end{array}$ & $\begin{array}{l}\text { Wavelength } \\
\text { (m) }\end{array}$ & $\begin{array}{l}\text { Wave } \\
\text { encounter } \\
\text { period }\end{array}$ & $\begin{array}{l}\text { Wave } \\
\text { steepness }\end{array}$ \\
\hline 1 & Stationary & 25.812 & - & 25.812 & - & - & - & - \\
\hline \multirow{3}{*}{2} & $\lambda / \mathrm{L}=0.9$ & 13.454 & 12.358 & 25.812 & 2.081 & 124.848 & 4.744 & $1 / 60$ \\
\hline & $\lambda / \mathrm{L}=1$ & 13.454 & 12.358 & 25.812 & 2.312 & 138.720 & 5.124 & $1 / 60$ \\
\hline & $\lambda / \mathrm{L}=1.2$ & 13.454 & 12.358 & 25.812 & 2.774 & 166.463 & 5.845 & $1 / 60$ \\
\hline
\end{tabular}

The standard SFS2 ship geometry modelled by Zan (2005), as shown in Figure 2, was used in the present study. The geometry contains only the section above the waterline because it was developed for the airwake analysis over its flight deck in the stationary condition. It is important to note that no other previous studies have been conducted using this geometry with coupled ship motions. Therefore, the above-waterline segment was integrated with an underwater hull form.

The underwater hull form was designed by taking an existing hull form from the naval architecture software MAXSURF reference design library (Bentley Systems, 2016) and integrated with the SFS2 geometry. The hull form was "oriented" in a 3D environment such that it matches with the length and breadth of the SFS2 geometry using CAD software Rhinoceros. The resulting draught of the ship was taken as the draught of the new geometry, which is shown in Figure 3. The principal characteristics of the ship can be found in Table 2. 


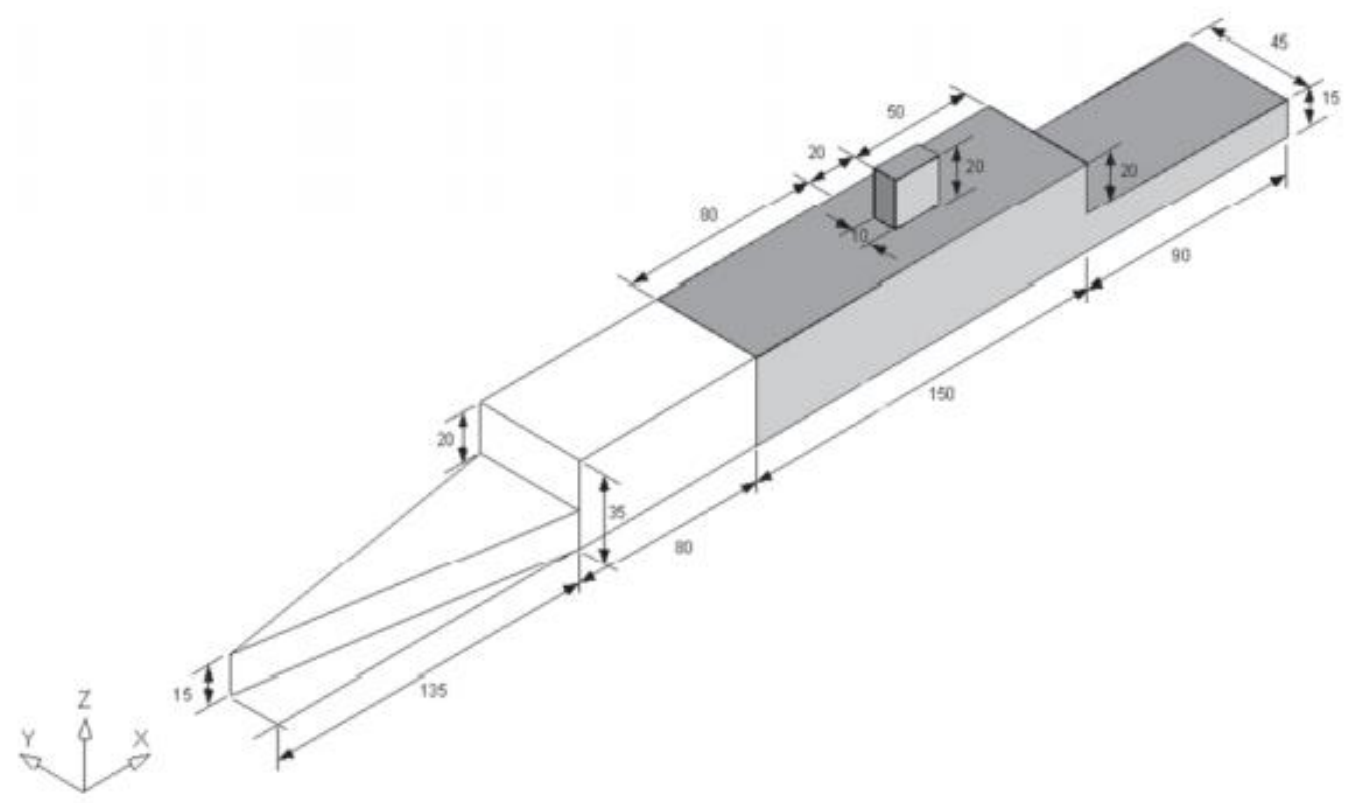

Figure 2. The SFS2 geometry. Original SFS geometry is shown in grey colour (Zan, 2005). Note that measurements are given in feet.

Table 2. Main dimensions of the integrated ship geometry used in this study

\begin{tabular}{|l|l|l|l|}
\hline Description & Symbol & Value & Unit \\
\hline Length between perpendiculars & L & 137.733 & $\mathrm{~m}$ \\
\hline Beam at waterline & $\mathrm{B}$ & 13.914 & $\mathrm{~m}$ \\
\hline Depth & $\mathrm{D}$ & 14.610 & $\mathrm{~m}$ \\
\hline Design draught & $\mathrm{T}$ & 10.200 & $\mathrm{~m}$ \\
\hline Displacement & $\Delta$ & $13,602.800$ & $\mathrm{t}$ \\
\hline Block coefficient & Cв & 0.680 & - \\
\hline Ship wetted surface area & S & $7,106.000$ & $\mathrm{~m}^{2}$ \\
\hline Longitudinal centre of buoyancy (\%L, fwd + ) & LCB & 44.520 & $\%$ \\
\hline Longitudinal centre of gravity from aft peak & LCG & 61.308 & $\mathrm{~m}$ \\
\hline Vertical centre of gravity from keel & KG & 6.800 & $\mathrm{~m}$ \\
\hline Metacentric height & GM $\mathrm{t}$ & 5.912 & $\mathrm{~m}$ \\
\hline
\end{tabular}




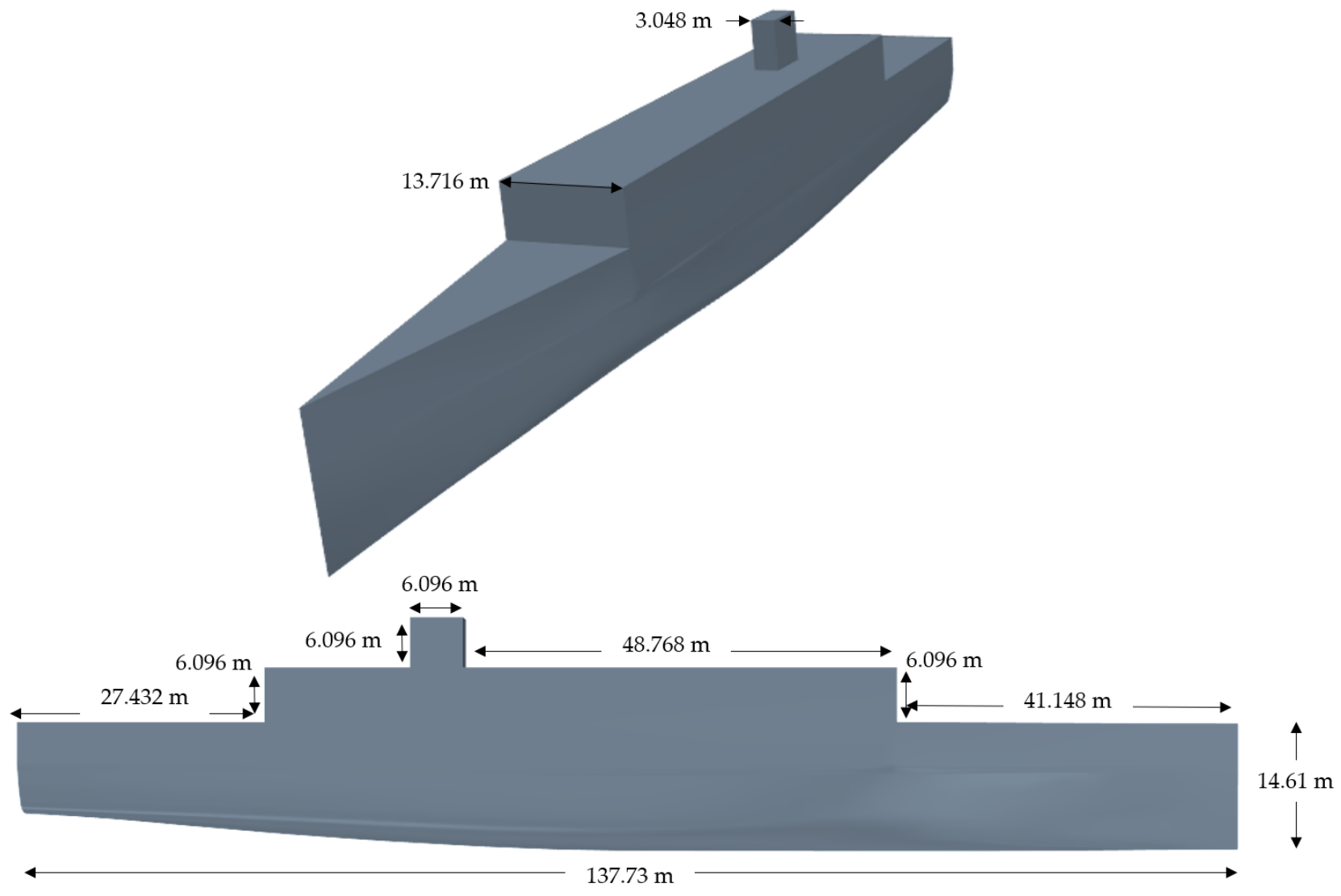

Figure 3. A 3D view of the integrated-SFS2 ship geometry used to conduct the simulations in waves.

\subsection{Numerical Modelling}

This section contains details of the numerical modelling, implemented in the present study. All numerical simulations were performed within the commercial Reynold-Averaged Navier Stokes (RANS) solver, Star-CCM+, version 15.02.007. To begin with, the governing equations are briefly summarised, following which, emphasis is given on the physics modelling, computational domain and the boundary conditions.

\subsubsection{Governing equations}

Detached Eddy Simulation (DES) used in the present study to model the flow. This approach utilises both RANS and Large Eddy Simulation (LES) approaches in a single setup. The averaged continuity 
and momentum equation of RANS for incompressible flow can be written in the tensor form and cartesian coordinates as shown in Eq. (3) and Eq. (4) (Ferziger and Peric, 2002):

$\frac{\partial\left(\rho \overline{u_{l}}\right)}{\partial x_{i}}=0$

$\frac{\partial\left(\rho \overline{u_{l}}\right)}{\partial t}+\frac{\partial}{\partial x_{j}}\left(\rho \overline{u_{l}} \overline{u_{J}}+\rho \overline{u^{\prime}{ }_{l} u_{J}^{\prime}}\right)=\frac{\partial \bar{p}}{\partial x_{i}}+\frac{\partial \bar{\tau}_{i j}}{\partial x_{j}}$

where $\mathrm{p}$ denotes the mean pressure, $\overline{u_{\imath}}$ denotes the averaged cartesian components of the velocity vector, $\rho \overline{u^{\prime}{ }_{\imath} u_{j}^{\prime}}$ are the Reynolds stresses, $\rho$ is the fluid density and $\bar{\tau}_{i j}$ denotes the mean viscous stress vector components as shown in equation (5).

$\bar{\tau}_{i j}=\mu\left(\frac{\partial \bar{u}_{i}}{\partial x_{j}}+\frac{\partial \bar{u}_{j}}{\partial x_{i}}\right)$

where $\mu$ represents the dynamic viscosity.

The governing equation for LES is the spatially filtered Navier Stokes equation. Therefore, the filtered equation of continuity and momentum for incompressible flow is (Zhang et al., 2018):

$\frac{\partial\left(\bar{u}_{i}\right)}{\partial t}+\frac{\partial}{\partial x_{j}}\left(u_{i} u_{j}\right)=-\frac{1}{\rho} \frac{\partial \bar{p}}{\partial x_{i}}+v \frac{\partial^{2} \bar{u}_{i}}{\partial x_{j} \partial x_{j}}-\frac{\partial \bar{\tau}_{i j}}{\partial x_{j}}$

$\frac{\partial \bar{u}_{i}}{\partial x_{i}}=0$

In Eq. (6) and (7), $\bar{u}_{i}$ and $\bar{p}$ denotes the resolved filtered velocity and pressure, respectively. The $\bar{\tau}_{i j}$ the term is as defined in Eq. (5). The diffusion term of the DES model can be defined as (Spalart, 2001):

$Y_{k}=\rho \beta \kappa \omega F_{D E S}$

$F_{D E S}=\max \left(\frac{L_{t}}{C_{D E S} \Delta_{\max }}, 1\right)$

where $\beta$ is a constant in SST model, $\kappa$ is the turbulent kinetic energy fluctuation, $\omega$ is the energy dissipation rate, $C_{D E S}=0.61, L_{t}$ is the parameter of turbulence defined in Eq. (10) and the $\Delta_{\max }$ is the local maximum grid map defined as $\Delta=\left(\Delta_{1} \Delta_{2} \Delta_{3}\right)^{\frac{1}{3}}$.

$L_{t}=\frac{\sqrt{\kappa}}{\beta^{*} \omega}$

When corrected for the delay option of the DES-SST, the new $F_{D E S}$ term becomes:

$F_{D E S}=\max \left(\frac{L_{t}}{C_{D E S} \Delta_{\max }}\left(1-F_{S S T}\right), 1\right)$

$F_{S S T}=0, F_{1}, F_{2} . F_{1}$ and $F_{2}$ represent the mixed functions of the SST model, which are applied to all simulations conducted in this work. 


\subsubsection{Physics Modelling}

To model the free surface, the Volume of Fluid (VOF) method available in the software package, Star-CCM+, was used to assign water and air phases within the domain (Hirt and Nichols, 1981). The method assigns a scalar value (volume fraction) to each cell, between 0 and 1 , indicating whether each cell is filled with air or water, respectively. A volume fraction of 0.5 indicates the position of the water-air interface. To re-create the regular waves within the virtual towing tank, $5^{\text {th }}$ order Stokes waves were chosen due the ability of the method to model waves that are more realistic and $1^{\text {st }}$ order methods (Tezdogan et al., 2016, 2015). Furthermore, a wave forcing option was applied to the outlet, side, and inlet boundaries of the domain. This is done to ensure the shape of the wave is not significantly affected in an adverse manner by grid coarsening, which occurs as one moves away from the ship structure, and to prevent wave reflections. In this approach, a source term is applied to the discretised form of the governing equations, which forces the solution to a simplified theoretical solution. Such an approach is beneficial to preserve the wave quality as a boundary is approached, as well as preventing wave reflections (Siemens, 2018).

\subsubsection{Computational domain and boundary conditions}

Two different domains were used in this study: one for the stationary case and a separate domain for simulations in waves. A single mesh was used for the stationary setup, whereas, in the case of the simulations in waves, a smaller overset mesh surrounding the ship geometry, within the main computational domain, was used to predict the ship motion accurately. The overset mesh encompasses the whole ship body and moves with the ship. In all cases, the mesh obtained from the stationary case is replicated to the greatest extent possible in the overset domain of the simulations in waves. The differences stem from additional refinements required for capture of the free surface. The overset mesh encloses the volume surrounding the ship super-structure such that the concerned air flow field, wave breaking, wave slamming and both the hydrodynamic and aerodynamic flow separation and vortices around the hull are well captured with motion.

\subsubsection{Computational domain}

In a hydrodynamic perspective, where the simulation involves waves, (ITTC, 2011) recommends placing the inlet locations at 1-2L away from the hull. Similarly, the recommended location of the pressure outlet is 3-5L downstream of the aft end of the ship. Several studies conducted on analysing ship airwake (Mateer et al., 2018; Reddy et al., 2000; Scott et al., 2015; Syms, 2008; Tai and Carico, 1995) show that the longitudinal span of the domain is between 2.5-6 Lвр. The half breadth of the domain used in the aforementioned studies varies between 1.46-7.5L. Note that the half breadth 
measurement is mentioned here because this work's CFD simulations were performed for half of the geometry, with a symmetry plane coincident with the ship centreline. A discussion on the imposition of such a boundary, coincident with the ship centreline is given in the results section. The domain height range was found to be within 0.63-3.7 Lв. Also, note that the height is measured from the surface of the water upwards.

For the stationary ship case in the current study, both inlet and outlet were placed 3L distance away from the hull, where a velocity inlet and pressure outlet conditions were imposed, respectively. The sidewall and domain top were placed 1.5LвP away from the central symmetry plane and water surface, respectively, with a velocity inlet condition imposed on both boundaries. Here, a velocity vector equal to the free stream is assigned in the negative $x$ direction only, i.e. approximating an infinite domain. For the simulations in waves, the inlet was placed at 1.5Lвр upstream of the forward perpendicular, while the pressure outlet is located at $4.5 \mathrm{LBP}$ downstream of the aft perpendicular. The bottom surface was placed at a depth of $2.5 \mathrm{~L}$ вр from the waterline to insure against shallow water effects. The upper boundary was located at $1 \mathrm{~L}_{\text {вр }}$ away from the water surface while the sidewall was placed 2.5Lвр away from the symmetry wall at centreline of the ship geometry. Figure 4 shows the dimensions of the computational domain and the corresponding boundary conditions.
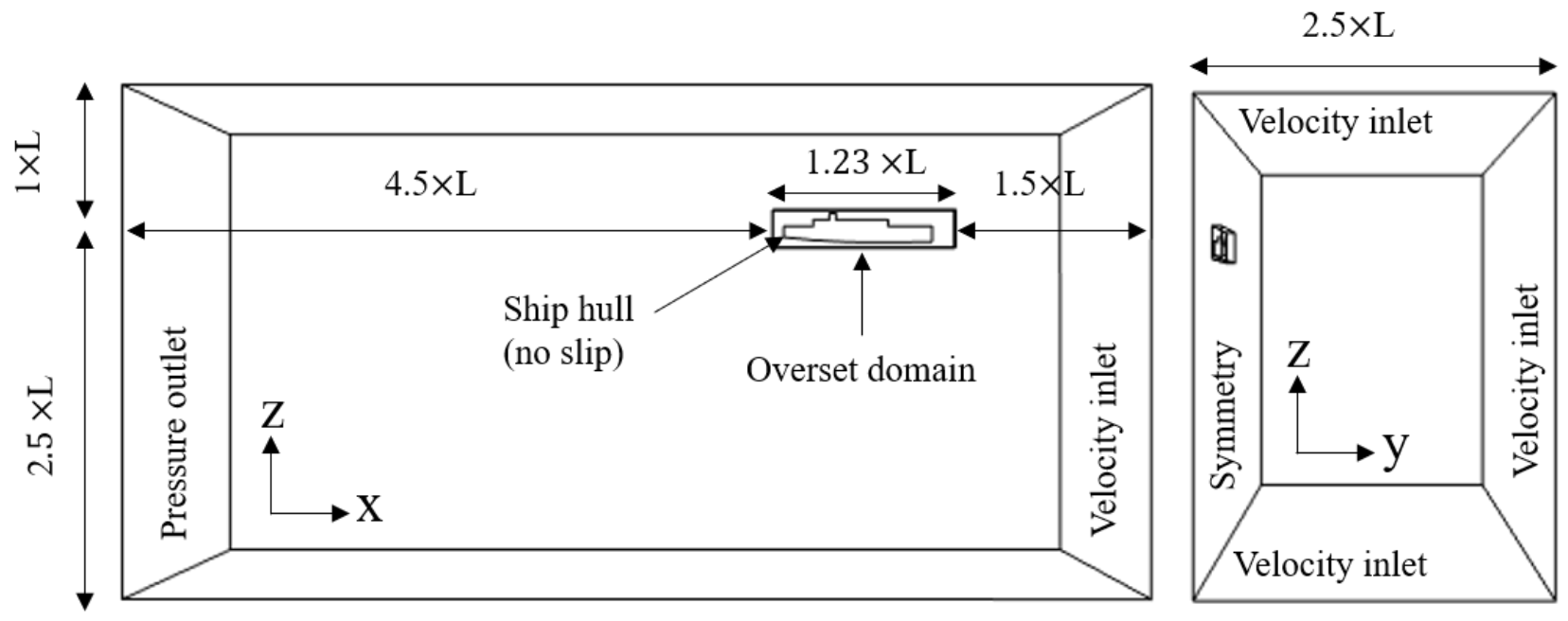

Figure 4. Dimensions and boundary conditions of the computational domain for simulating the head seas condition.

The key assumptions made within this section are summarised as follows:

- The flow is symmetric about the ship centerline. This allowed the positioning of a symmetry plane, thereby reducing the mesh requirements by $50 \%$. 
- The computational domain of size $6 \mathrm{~L} \times 2.5 \mathrm{~L} \times 3.5 \mathrm{~L}$ is sufficient to approximate an infinite sea. To aid in this, wave forcing was implemented on the side boundary, inlet and outlet.

- Implementing a velocity on the top, bottom, and side boundaries in the negative $x$ direction forces the flow to its free stream, thereby approximating an infinite sea in all directions.

\subsubsection{Mesh generation}

Meshing techniques employed by (Tezdogan et al., 2016, 2015) were taken as a base reference in preforming the mesh generation in this study. The automatic meshing facilities of STAR-CCM+ were employed to generate the computational mesh. The trimmed cell mesh technique was used to provide a predominantly hexahedral unstructured mesh. Further mesh refinements were applied to the free surface area, the area surrounding the hull to include the airwake region and in the hydrodynamic wake region for the simulations in waves.

In terms of the near-wall grid, an order of magnitude $O(10)$ was used in this simulation due to the difficulty in achieving $y^{+}<1$ in full-scale. Ideally, a $y^{+}<1$ is sought, but for full-scale flows, or high Reynolds number flows, the number of cells becomes prohibitively high (Liefvendahl and Fureby, 2017). For this reason, a wall function approach was used, following Forrest and Owen (2010), where the average $y^{+}$on the ship hull was $y^{+}=50$. In the present simulations, the average $y^{+} \approx 53$, the distribution of which is shown in Figure 5. The resulting mesh for the simulations in waves is shown in Figure 6. The resulting total number of cells for the stationary cases was 12,706,633, whereas the simulations in waves featured 15,039770 cells. 


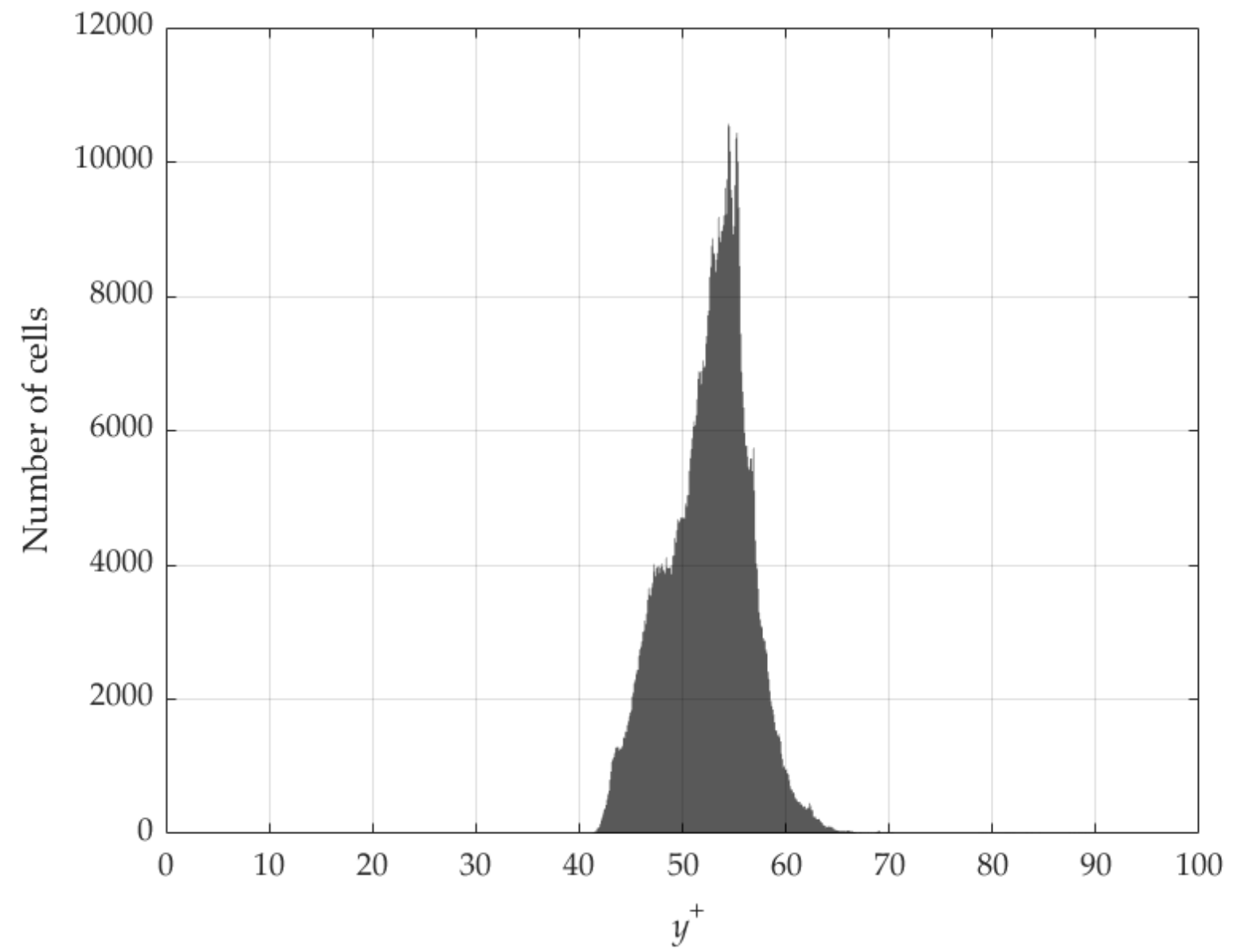

Figure 5. Example $y^{+}$distribution on the hull. 

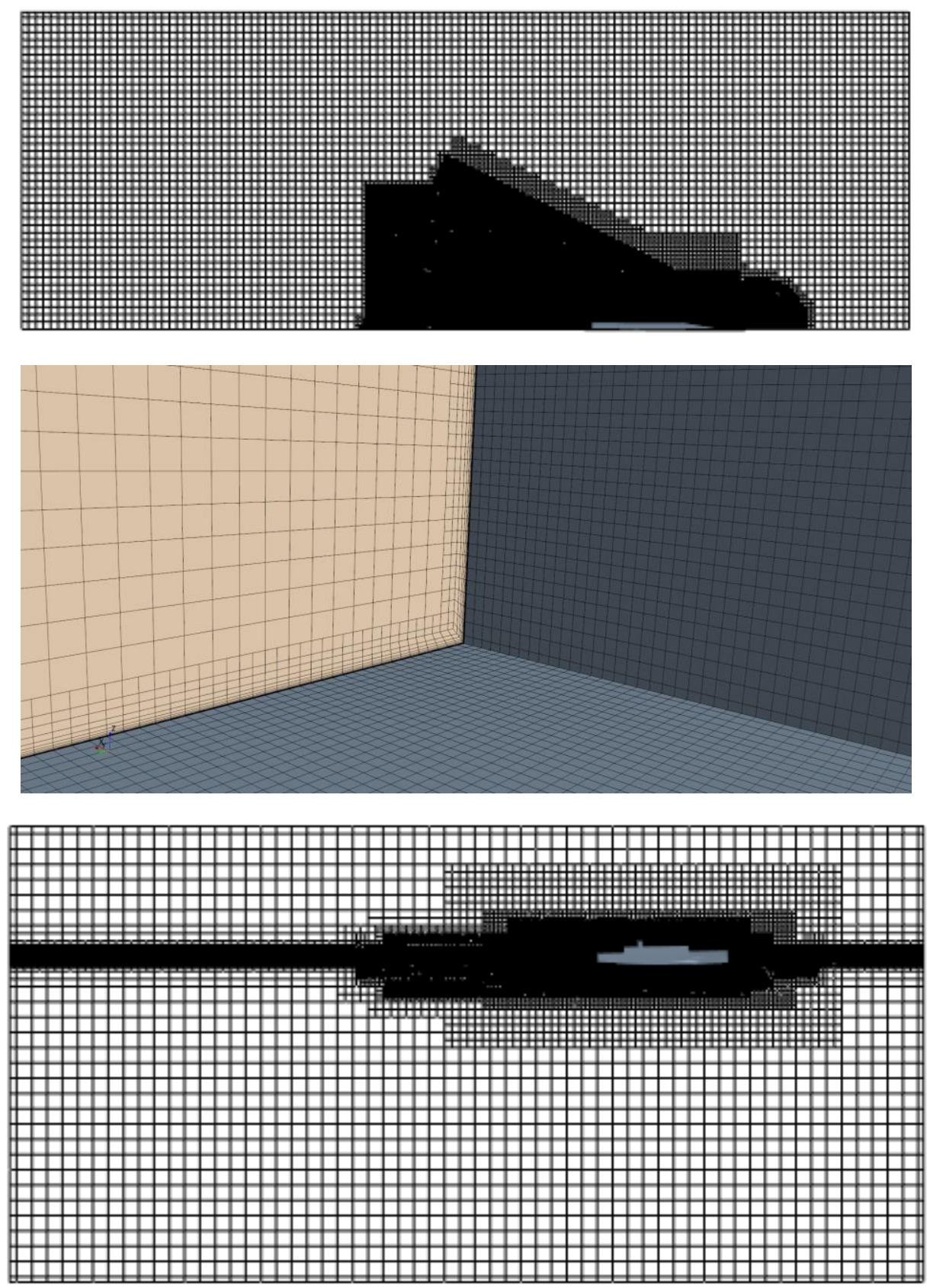

Figure 6. The computational mesh. Top - mesh on the mean waterline; middle - close-up of the funnel mesh; bottom - mesh on the symmetry plane.

\subsubsection{Time-step selection}

There are two considerations in selecting the time-step for the present simulations. Firstly, the timestep should be small enough to capture the dominant vortex frequencies and large enough to prevent 
high computational time and cost (Durbin and Pettersson Reif, 2011) and (Forrest et al., 2012). A relatively higher time-step may also lead to the instability of the numerical scheme (Shukla et al., 2019). To set a suitable time-step in simulating airwake of ships, (Forrest et al. (2012) suggest using a time-step of $1 / 20^{\text {th }}$ of the shedding period. As the current study is concerned about capturing the vortex within the frequency range of $0.2-2 \mathrm{~Hz}$ where vortex shedding has the highest impact on pilot workload (McRuer, 1994), the shedding period would be 5-0.5s. Therefore, the corresponding minimum $1 / 20^{\text {th }}$ time-step would be $0.025 \mathrm{~s}$.

From a hydrodynamic perspective, (Tezdogan et al., 2015) recommended a time-step of $\Delta t=T_{e} / 2^{9}$, where $T_{e}$ is the encounter period. On the other hand, the International Towing Tank Conference (ITTC, 2011) recommended using 100 time-steps per encounter wave period in simulating ship response to incident regular waves, i.e. $\Delta t=T_{e} / 100$. As shown in Table 1 , the encounter wave periods are $4.74 \mathrm{~s}, 5.12 \mathrm{~s}$ and 5.85s. According to ITTC (2011) the respective minimum time-steps for these wave periods can be calculated as $0.0474 \mathrm{~s}, 0.0512 \mathrm{~s}$ and $0.0585 \mathrm{~s}$.

To ensure both aero and hydrodynamic requirements are satisfied, the selected time-step was calculated using the formula $\Delta t=\left(1.88 \times B \times 10^{-2}\right) / V_{\text {ref }}$ where B is the beam of the ship (Forrest and Owen, 2010). The resulting time-step was 0.01013 s which was used in all cases for consistency. This also passes the criteria and recommendations obtained from the ITTC (2011), Forrest and Owen (2010), and Tezdogan et al. (2015).

\subsection{Measurement locations}

As stated earlier, velocity data is recorded at specific locations for which, in the stationary ship case, comparison with experimental data is possible. The locations where the data was measured for is located at discrete points in the aft section of the ship. Specifically, aft of and at a height equal to that of the hangar. Two sets of longitudinal positions are given: at 50\% flight deck length, and at $25 \%$ flight deck length. A visual aid in describing the position of these points is given in Figure 7, where the points are shown distributed over a lateral distance equal to $2 \times \mathrm{B}$. 


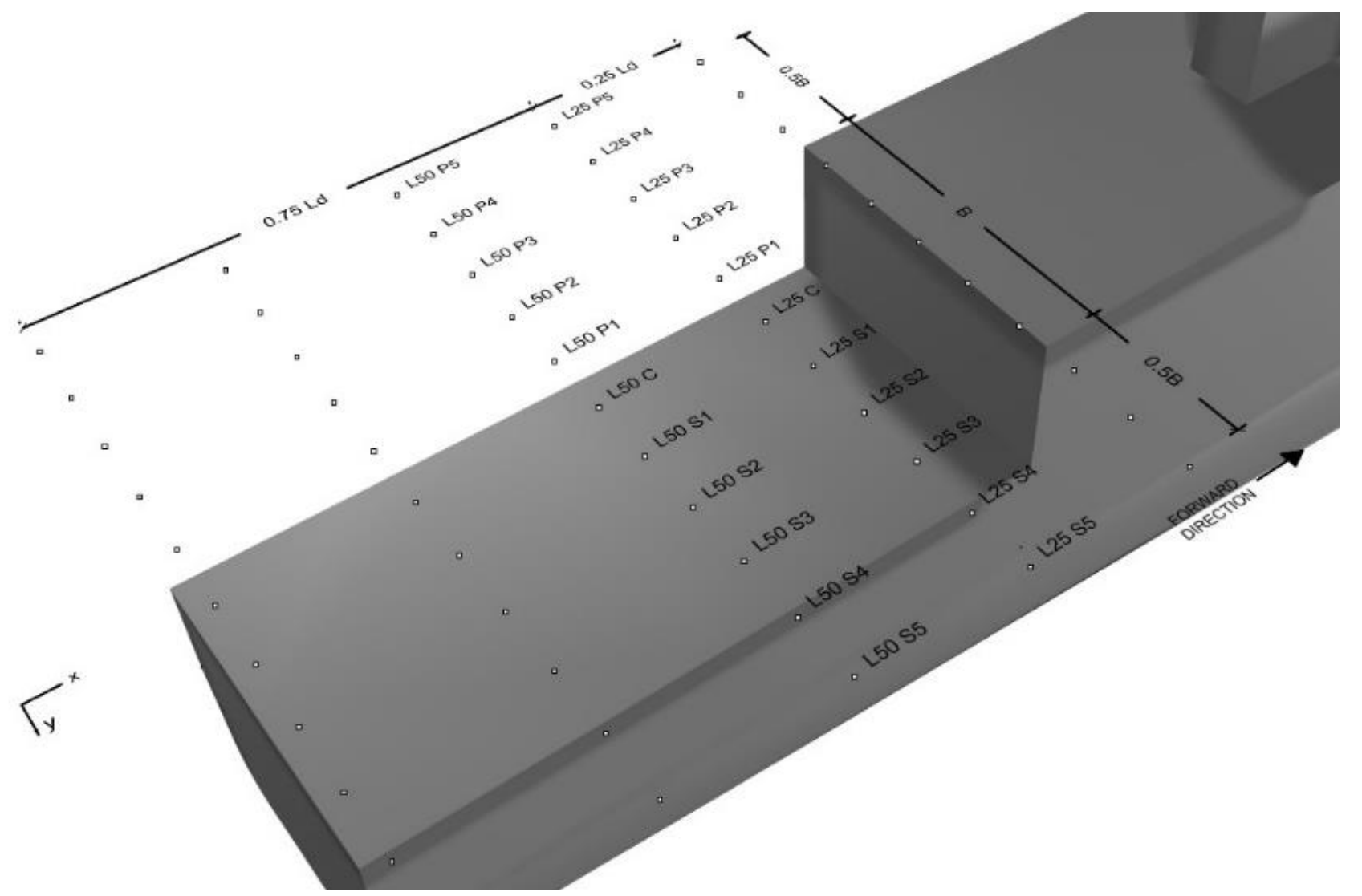

Figure 7. Measurement probe locations over the flight deck (perspective). Here, "B" denotes the ship breadth and "Ld" denotes the length of the flight deck

The points are labelled based on their location, i.e. the points coincident with the centreline read L50C and L25C, representing the \% length and position. This is analogously done for the points on the port $(\mathrm{P})$ and starboard side $(\mathrm{S})$. These same locations described above are used in all simulations. The coordinates, representing the location of each point are linked to the global coordinate system, i.e. they do not move in compliance to the ship's vertical wave-induced motion.

The measured data from the case where the ship is stationary are subsequently compared with experimental results from Cheney and Zan (1999). As the integrated-SFS2 model is a newly developed geometry, no experiment has been performed to assess the airwake behind the integrated-SFS2 ship in motion yet. Therefore, the simulations in waves are not compared against experimental data. 


\section{Results and Discussion}

This section is split into three major parts. Firstly, a validation is presented using the velocity data at the previously mentioned locations in the form of comparison with experimental data. Following this, a verification exercise is given for two cases that are treated as representative. Finally, parametric studies are described.

\subsection{Validation}

In this section, the first item to be presented is the averaged velocity data. The previously mentioned points at $25 \%$ and $50 \%$ deck length are used, for which experimental data is available in the stationary case. Figure 8 shows the averaged velocity data obtained for the stationary ship with and without the presence of an atmospheric boundary layer. Here, the data obtained within this study is compared with experimental data. Although the asymmetry in the results is not reproduced in this work, the produced set of $V / V_{\infty}$ (where $V$ is the velocity at a particular location while $V_{\infty}$ is the free stream velocity) results shows good agreement with the experimental results when modelled without an atmospheric boundary layer. When the ABL is included in the simulation, the dimensionless velocity values show a reduction or offset of approximately $0.1 \mathrm{~V} / \mathrm{V}_{\infty}$ throughout the examined range of $\mathrm{y} / \mathrm{b}$ values.

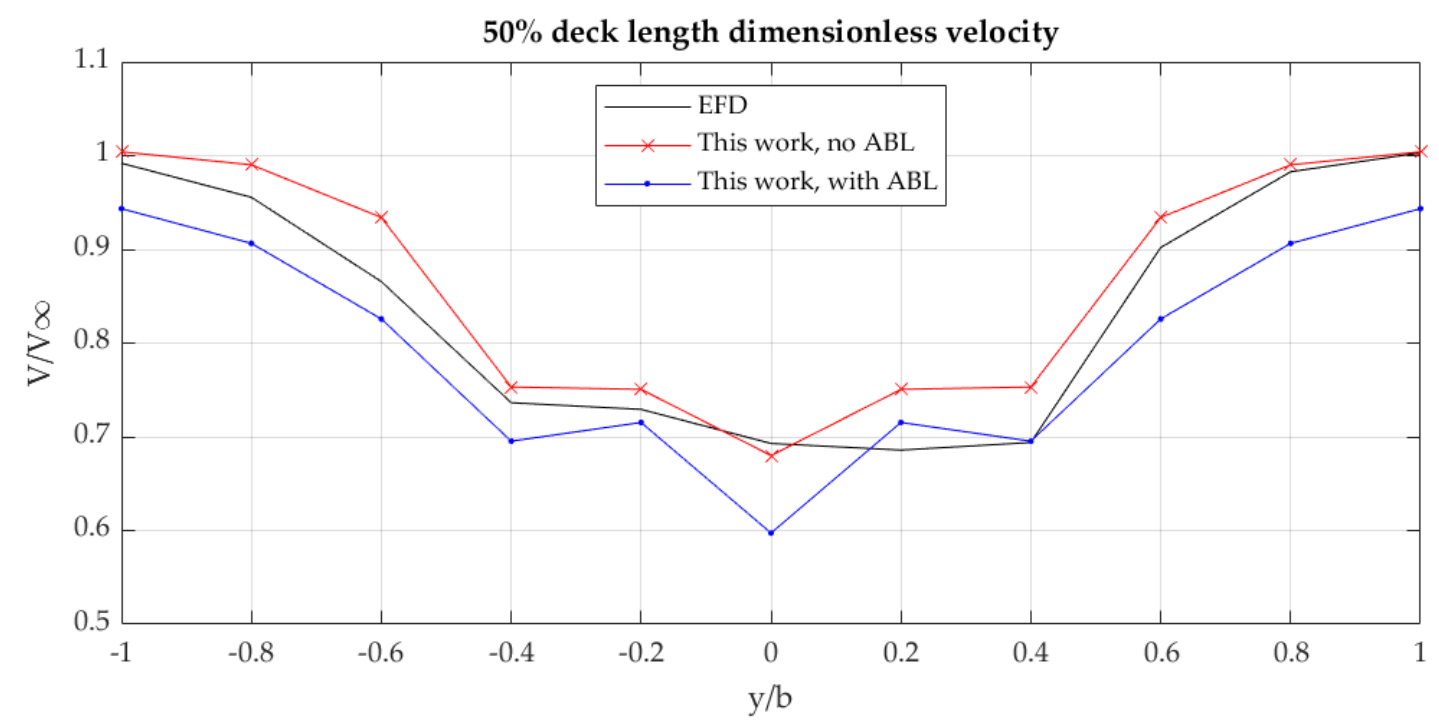

Figure 8. Dimensionless velocity profile at 50\% deck length and comparison with other experimental and numerical studies. 


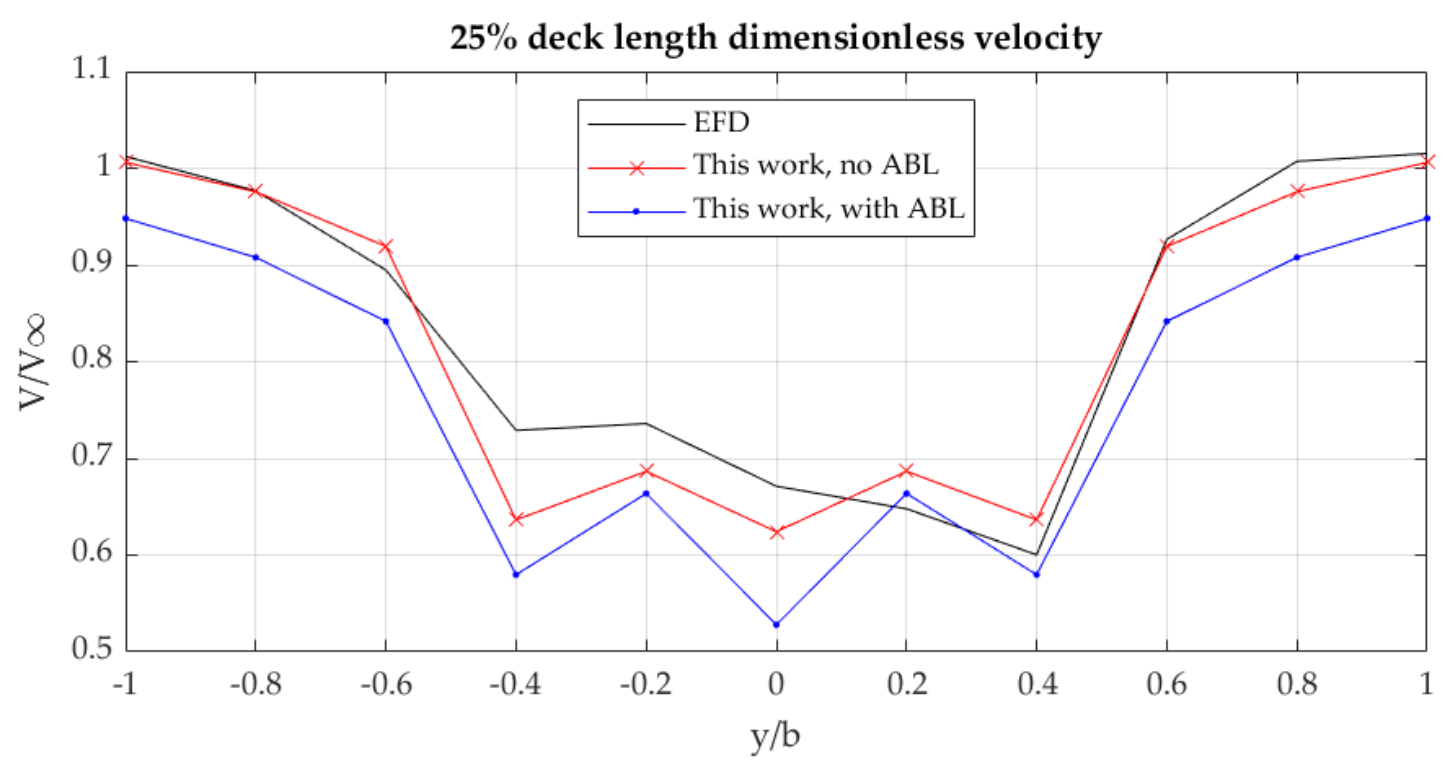

Figure 9. Dimensionless velocity profile at $25 \%$ deck length and comparison with other experimental and numerical studies

Figure 9 depicts the obtained dimensionless velocity profiles for the points located at $25 \%$ deck length. As was the case in Figure 8, the simulation where an atmospheric boundary layer was modelled shows a reduction in the dimensionless velocity. In Figure 9, this offset is not as uniform across the $y / b$ range as in Figure 8, with little difference shown at $|y / b|=0.2$. The values obtained for the case without an ABL show good agreement over the entire range of experimental data, although the asymmetry is again not replicated due to the imposition of the symmetry plane. This is consistent with the fact that during the experiment, boundary layer suction was, thereby removing the atmospheric boundary layer effects.

Imposing a symmetry plane coincident with the ship centreline is clearly a factor in the observed differences between the experimental data, and that obtained herein. It is therefore worthwhile to comment on the appropriateness of the technique. On the one hand, one can create considerable mesh refinements in the vicinity of the ship to ensure a good representation of the flow features due to the savings in cell numbers. Since the relationship between efficiency and cell numbers is sublinear, particularly for large simulations, it is highly desirable to maintain the cell numbers as low as possible. On the other hand, the experimentally obtained flow is asymmetric and would ideally require the geometry to be fully modelled. The reason why the adopted approach is considered appropriate lies in the relatively small deviations between experimentally determined dimensionless velocities at $\pm \mathrm{y} / \mathrm{b}$ pairs for the $50 \%$ deck length case. 
The experimental data for the $25 \%$ deck length case is characterised by a greater degree of asymmetry. Regardless, the numerical values obtained in the course of this study show good agreement over the majority of the $y / b$ range. Therefore, it can be concluded that the inclusion of a symmetry plane is justifiable for cases where the cell numbers become prohibitively high. This is to be balanced with the potential deterioration in flow feature quality, particularly in the immediate vicinity of the symmetry plane

\subsection{Verification}

This section is dedicated to the estimation of the numerical uncertainty, stemming from the choice of grid spacing and time step. The approach adopted to estimate the uncertainty is the Grid Convergence Index (GCI), which is considered the standard way of reporting numerical uncertainty in CFD (Roache, 1998). This procedure begins by magnifying the typical cell size, or time step by a constant refinement factor. In this study, the refinement factor $(r)$ is chosen as $r=\sqrt{2}$, following the recommendations of the (ITTC, 2017). The analysis is carried out on two cases, which are treated as representative. Specifically, the case where the ship stationary, and in waves with $\lambda=1.2 \times L$.

The uncertainty analysis requires the grid and time step to be magnified by the refinement factor twice successively to produce a medium $\left(f_{2}\right)$ and coarse $\left(f_{3}\right)$ solution, to be used with the fine solution $\left(f_{1}\right)$. Then, the observed order of accuracy may be defined as shown in Eq. (12).

$p=|\ln | \varepsilon_{32} / \varepsilon_{21}|+q(p)| / \ln r_{21}$

where $\varepsilon_{32}=f_{3}-f_{2}, \varepsilon_{21}=f_{2}-f_{1}$, and the function $q(p)=0$ when $r_{21}=r_{32}$, i.e. the refinement factor employed is constant which is the case here (Celik et al., 2008). Next, one can define the extrapolated solution as shown in Eq. (13).

$f_{\text {ext }}=\left(r_{21}^{p} f_{1}-f_{2}\right) /\left(r_{21}^{p}-1\right)$

Finally, the grid or time step induced uncertainty is predicted as shown in Eq. (14):

$G C I=1.25\left|\frac{f_{1}-f_{2}}{f_{2}}\right| \times \frac{1}{r_{21}^{p}-1}$

The standard notation is used to facilitate the readability and potential comparison with future studies. The abbreviation GCI is used to denote the uncertainty, while $U_{c}=\left(G C I_{\text {grid }}^{2}+G C I_{\text {time }}^{2}\right)^{1 / 2}$ is the combined spatiotemporal uncertainty.

To perform the uncertainty analysis, the set of points, lying at 50\% of the deck length are chosen. The grid numbers for the stationary case were 5,610,836 and 2,216,984 cells, while the simulation in waves featured $6,424,753$, and $3,110,179$, for the medium and coarse cases, respectively. In 
coarsening the mesh, the finest time step was maintained in an attempt to isolate the grid-induced uncertainty. Conversely, the finest mesh was used while magnifying the time step by the same refinement factor. The results from the uncertainty analysis are given in Table 3.

The results given in Table 3 suggest that the present set of simulations tends to be more sensitive to changes in the mesh, rather than time. The highest mesh dependence observed for the stationary ship is approximately $8.6 \%$ for point 3 , while the greatest mesh dependence for the simulation in waves is $7.43 \%$ in the case of point 1 . The time dependence of the solution tends to be considerably weaker in the stationary case, where no points exceeds an uncertainty of $0.539 \%$ (recorded for point 4). On the other hand, the time dependence of the simulation featuring waves exhibits a maximum uncertainty of $5.459 \%$, which is one order of magnitude greater than for the stationary ship. This suggests that the recommendations of Forrest and Owen (2010) for setting the time-step are highly efficient when the ship is stationary, which is the case they examined. However, a further reduction may be necessary to achieve the same level of numerical confidence in the solution when the ship is subjected to head waves.

Table 3. Time and grid dependence test for the stationary ship and in waves for $\lambda=1.2 \times L$

\begin{tabular}{|c|c|c|c|c|c|c|c|c|c|c|c|c|}
\hline \multirow{2}{*}{ Variable } & \multicolumn{2}{|c|}{ Point 1} & \multicolumn{2}{|c|}{ Point 2} & \multicolumn{2}{|c|}{ Point 3} & \multicolumn{2}{|c|}{ Point 4} & \multicolumn{2}{|c|}{ Point 5} & \multicolumn{2}{|c|}{ Point 6} \\
\hline & Time & Grid & Time & Grid & Time & Grid & Time & Grid & Time & Grid & Time & Grid \\
\hline \multicolumn{13}{|c|}{ Stationary case } \\
\hline Fine & \multicolumn{2}{|c|}{0.680} & \multicolumn{2}{|c|}{0.751} & \multicolumn{2}{|c|}{0.753} & \multicolumn{2}{|c|}{0.934} & \multicolumn{2}{|c|}{0.990} & \multicolumn{2}{|c|}{1.00} \\
\hline Medium & 0.677 & 0.713 & 0.743 & 0.741 & 0.748 & 0.701 & 0.928 & 0.926 & 0.988 & 0.997 & 1.009 & 1.012 \\
\hline Coarse & 0.599 & 0.612 & 0.710 & 0.602 & 0.643 & 0.580 & 0.912 & 0.902 & 0.980 & 0.974 & 1.02 & 1.006 \\
\hline Extrapola & 0.6801 & 0.679 & 0.753 & 0.751 & 0.753 & 0.792 & 0.938 & 0.938 & 0.991 & 0.990 & 1.000 & 1.000 \\
\hline GCI (\%) & 0.032 & 0.330 & 0.505 & 0.158 & 0.055 & 8.640 & 0.539 & 0.591 & 0.106 & 0.031 & 0.488 & 0.044 \\
\hline$U_{c}(\%)$ & \multicolumn{2}{|c|}{0.3315} & \multicolumn{2}{|c|}{0.529} & \multicolumn{2}{|c|}{8.6402} & \multicolumn{2}{|c|}{0.800} & \multicolumn{2}{|c|}{0.110} & \multicolumn{2}{|c|}{0.490} \\
\hline \multicolumn{13}{|c|}{$\lambda=1.2 \times L$} \\
\hline Fine & \multicolumn{2}{|c|}{0.504} & \multicolumn{2}{|c|}{0.549} & \multicolumn{2}{|c|}{0.573} & \multicolumn{2}{|c|}{0.706} & \multicolumn{2}{|c|}{0.778} & \multicolumn{2}{|c|}{0.845} \\
\hline Medium & 0.595 & 0.574 & 0.699 & 0.698 & 0.693 & 0.69 & 0.808 & 0.79 & 0.873 & 0.825 & 0.923 & 0.883 \\
\hline Coarse & 0.546 & 0.452 & 0.557 & 0.538 & 0.609 & 0.595 & 0.769 & 0.733 & 0.821 & 0.829 & 0.869 & 0.88 \\
\hline Extrapolated & 0.633 & 0.639 & 0.771 & 0.768 & 0.735 & 0.736 & 0.814 & 0.830 & 0.897 & 0.890 & 0.924 & 0.920 \\
\hline GCI (\%) & 459 & 7.430 & 5.463 & 4.823 & 3.484 & 3.724 & 0.177 & 3.149 & 1.230 & 0.156 & 0.009 & 0.472 \\
\hline$U_{c}(\%)$ & \multicolumn{2}{|c|}{9.220} & \multicolumn{2}{|c|}{7.287} & \multicolumn{2}{|c|}{5.100} & \multicolumn{2}{|c|}{3.154} & \multicolumn{2}{|c|}{1.239} & \multicolumn{2}{|c|}{0.472} \\
\hline
\end{tabular}




\subsection{Parametric studies}

As stated at the onset of this work, comparison with experimental data is only possible when the ship is stationary, in other words, the ship is operating in the equivalent of calm water. However, to the best of the authors' knowledge, experiments of a ship undergoing vertical wave-induced motions have yet to be conducted. Therefore, it is not possible to perform the same comparison in what follows as was the case in Figure 8 and Figure 9. Nevertheless, it will be assumed that a similar degree of accuracy may be achieved in all cases. It is also hoped that the present work will create an increased interest in the field which can lead to an experimental campaign to determine the influence of vertical ship motions, or indeed 6 degree of freedom motion, on the airwake.

To begin with, the recorded heave and pitch time histories in waves are compared as obtained from the CFD simulations. Due to the strong headwind in which the ship is operating, the hydrodynamic behaviour of the ship is influenced and a difference may be detected between the cases where an atmospheric boundary layer is present versus those where it is not. The interaction between the airwake and the ship's vertical motions may be deduced from Figure 10. Here, the heave and pitch responses of the ship are given against the dimensionless encounter period of each case (refer to Table 1 for details). It should be noted that the only difference between the cases where an ABL is modelled, and one where it is not lies in the initial and boundary condition at the inlet. No changes or modification are applied on the grid, time step, or other numerical settings.
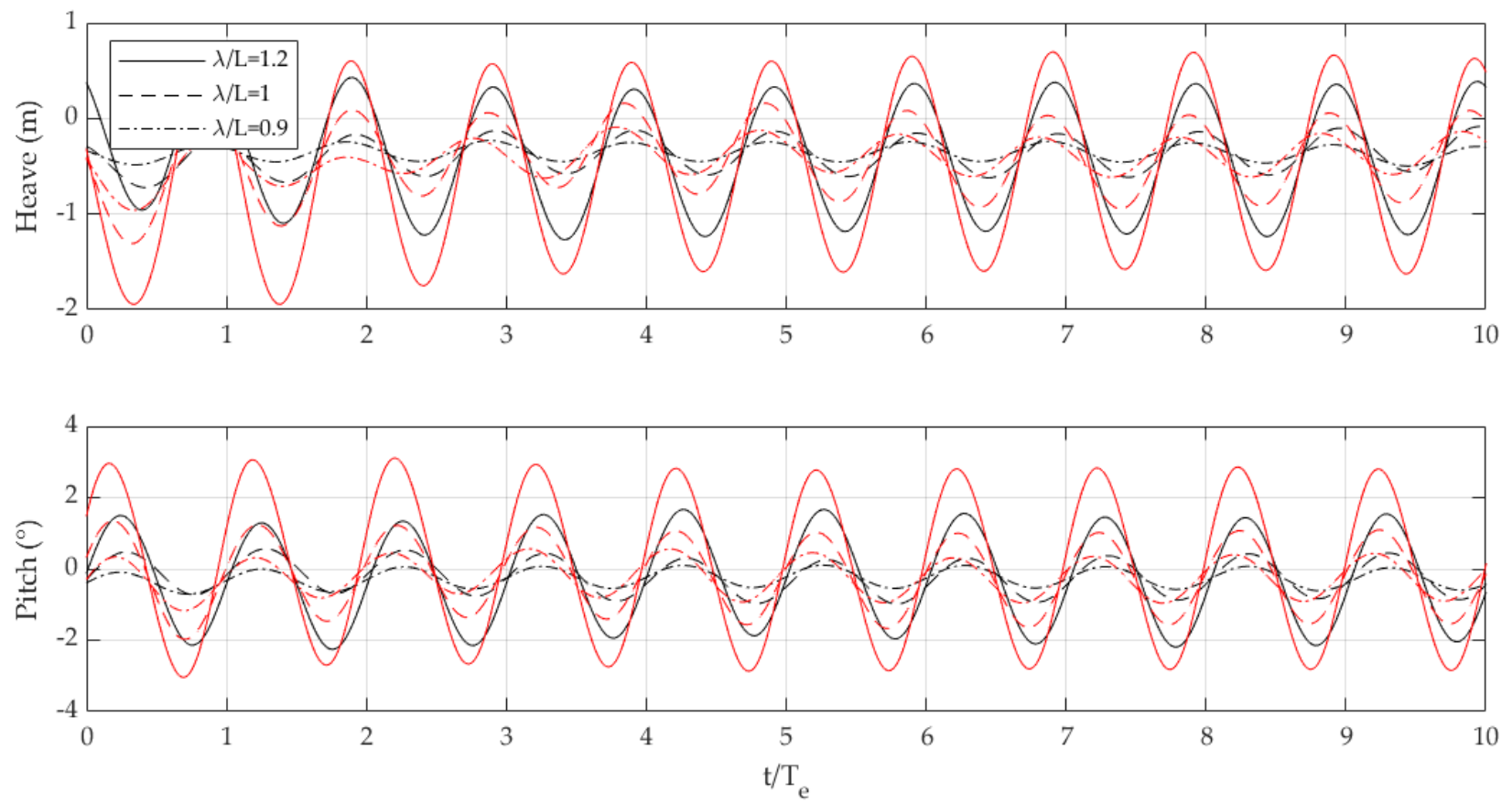
Figure 10. Heave (top) and pitch (bottom) responses of the ship about the LCF due to head waves without an atmospheric boundary layer (red curves), and in the presence of an atmospheric boundary layer (black curves).

By examining Figure 10, it immediately becomes apparent that the ship's motions are influenced significantly based on whether or not an atmospheric boundary layer is modelled. One key observation is that the heave and pitch curves are not affected in the same manner by the inflow condition. In the case of heave, the ship time history is dampened by between $20.9 \%$ and $22.39 \%$ for the $\lambda / \mathrm{L}=1.2$ and $\lambda / \mathrm{L}=1$ case, respectively, with $\lambda / \mathrm{L}=0.9$ lying in between these. That is, the presence of an atmospheric boundary layer reduces the motion amplitude by approximately $1 / 5$, when compared to a case where the atmospheric boundary layer is not modelled. It is thought that an ABL provides a type of cushioning effect as the ship heaves and pitches. In addition to the wind inducing a drag in the direction of motion, it also resists the ship's motion in heave and pitch, which is the primary mechanism by which the motions of the vessel are thought to be reduced. In any case, further investigations are required to confirm this.

In the case of the pitch, the time-history is affected differently depending on the $\lambda / L$ ratio. When the ship is subjected to waves of $\lambda / \mathrm{L}=1.2$, the highest pitch amplitude is observed, but the smallest decrease, of $20.7 \%$ in response is measured as a result of the modelling of an atmospheric boundary layer. On the other hand, although the response amplitude itself is considerably lower for the two shorter waves, the relative impact of the ABL is approximately $38.4 \%$ - nearly double the difference compared to $\lambda / \mathrm{L}=1.2$ when examining the shorter wave cases.

A more subtle impact of the choice of including an atmospheric boundary layer is expressed in the apparent difference in encounter period, which is difficult to detect in the $\lambda / \mathrm{L}=1.2$ case, but increases noticeably for shorter waves. Specifically, for $\lambda / L=1.2$, heave peaks occur at a relative distance of approximately $0.022 \times \mathrm{t} / \mathrm{T}_{\mathrm{e}}$, in the case of for $\lambda / \mathrm{L}=1$, the aforementioned peaks occur $0.077 \times \mathrm{t} / \mathrm{Te}$ apart, whereas for $\lambda / \mathrm{L}=0.9$, the corresponding value is $0.099 \times \mathrm{t} / \mathrm{Te}$. This is likely related to the amplitude of motion the ship experiences. Lower motion amplitudes are more susceptible to influences from the aerodynamics of the ship.

Next, the dimensionless velocities of the simulations in waves are given. These are presented as was done earlier for the stationary cases, namely, the data is split based on the location of the sampled points along the deck length. Firstly, the 50\% deck length dimensionless velocity is shown in Figure 11. The wavelength used to test the ship is highly impactful on the magnitude of the dimensionless velocity. The two case studies with relatively longer waves in the absence of an $A B L, \lambda / L=1.2$ and $\lambda / L=1$, the dimensionless velocities are offset lower than obtained with $\lambda / L=0.9$. Clearly, increasing 
the wavelengths decreases the velocity magnitudes in the entire range of $y / b$ values examined. The same hierarchy is observed in Figure 12, where the 25\% deck length values are given. Again, the simulations ran with a uniform flow field produce data arranged vertically in the $V / V_{\infty}$ scale, starting from short waves at the higher end of the scale and ending with long waves which have the effect of reducing the velocity magnitude.

The difference in the velocity magnitude observed in Figure 11 and Figure 12 in the case of uniform flow fields (no ABL) is directly correlated with the motion magnitudes shown in Figure 10. Increasing the motion amplitude of the ship means the points, which are set relative to the global coordinate system, spend time in close proximity to the ship structure when the ship amplitude reaches its peak in the case of heave. From the point of view of pitch, when the heave amplitude of the ship is low, the pitch is near its maximum. This creates the conditions where the globally-oriented locations aft of the ship operate within areas that are more affected by the airwake than is the case for a stationary ship (or a ship that does not move vertically).

It is important to note that selecting globally-oriented coordinates, or in other words, points that do not maintain a constant distance with respect to the ship structure, is a more physically consistent approach. The reason for this lies in the fact that a helicopter would not mimic ship motions prior to landing, and the pilot would be required to compensate manually for the observed velocity profile which they must operate in to land on the helideck.

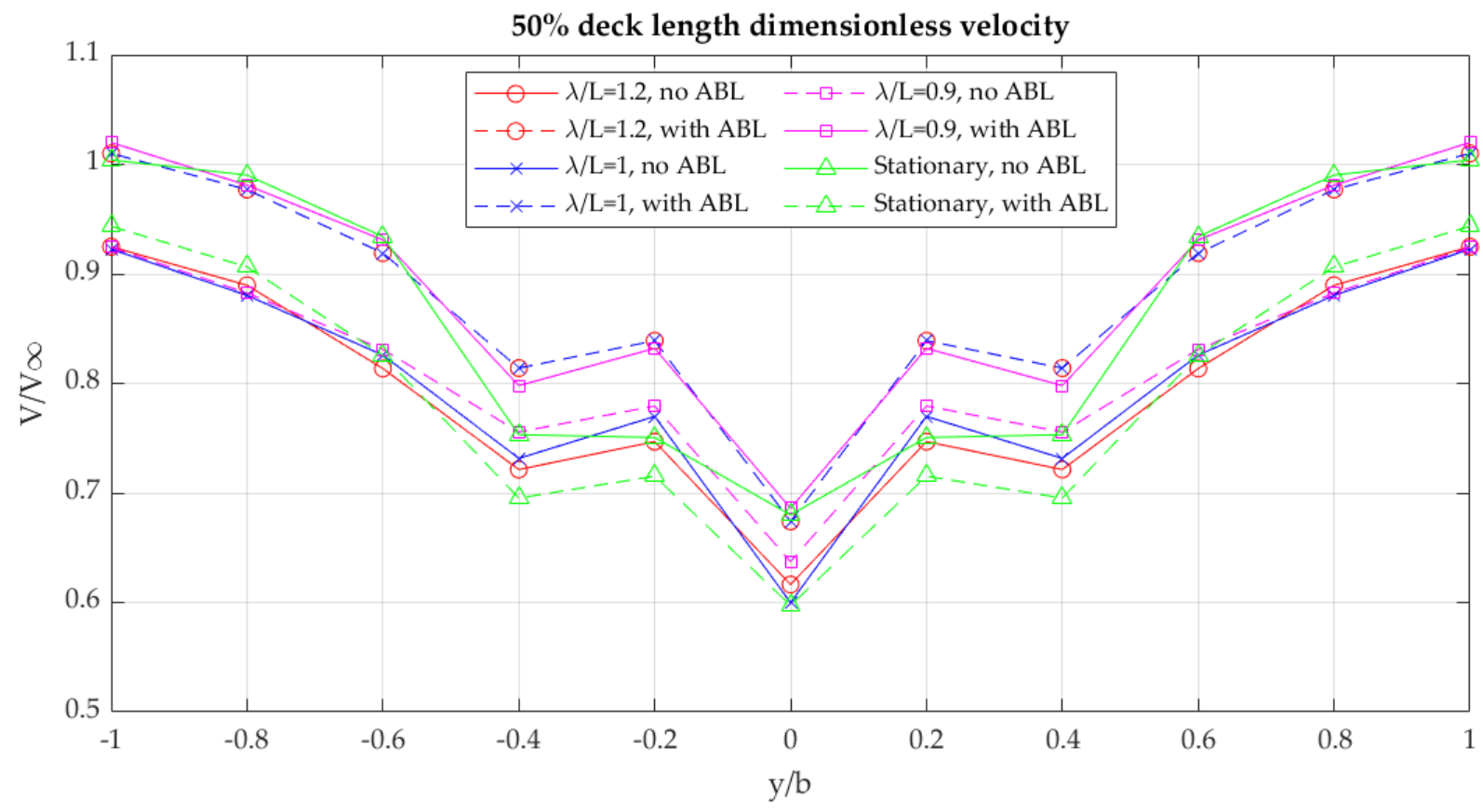

Figure 11. Dimensionless velocity profiles at 50\% deck length for all simulations in waves. 


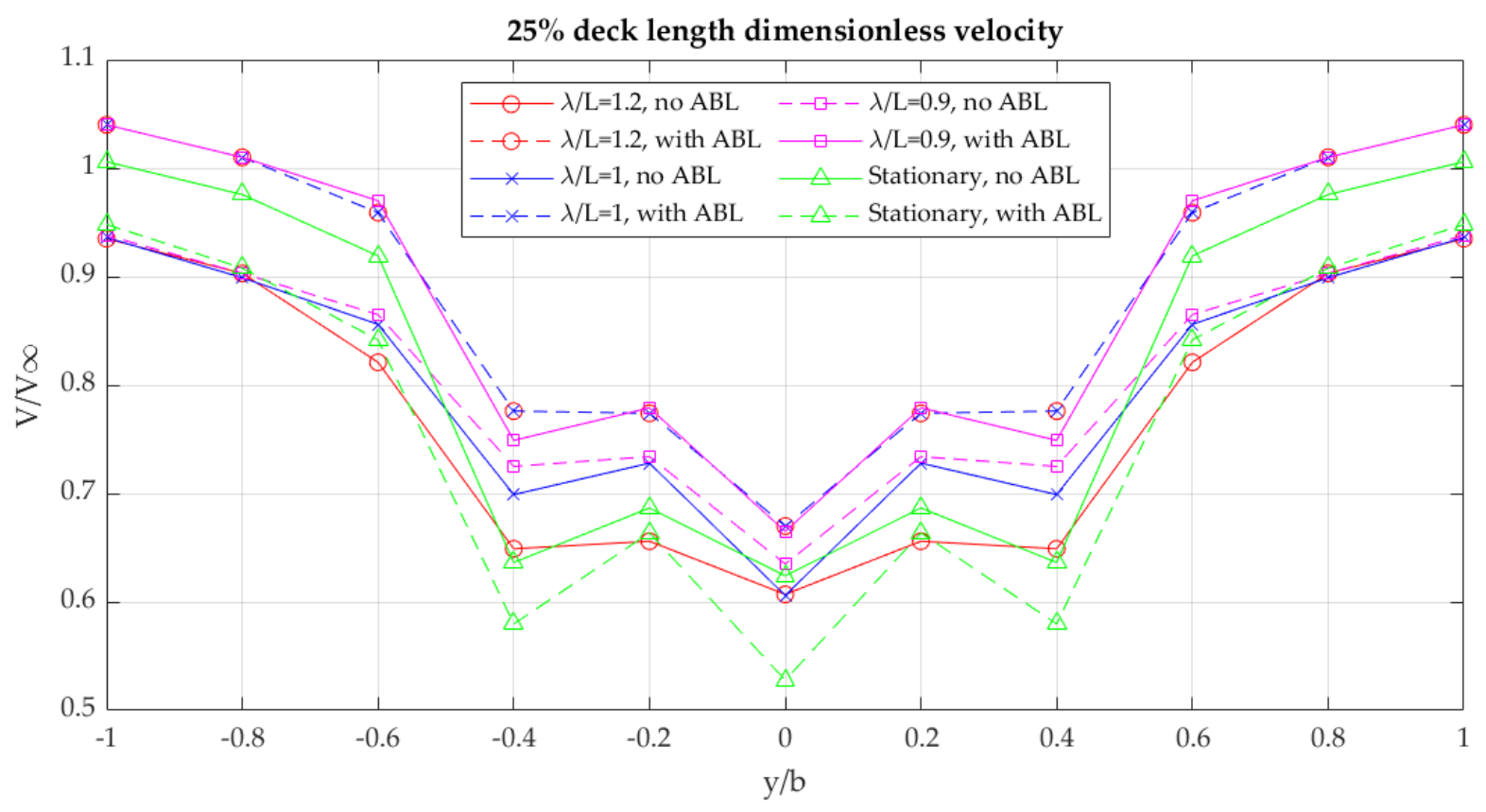

Figure 12. Dimensionless velocity profiles at $25 \%$ deck length for all simulations in waves.

Since this study is exploratory in the field, a single ABL profile is modelled. However, it is conceivable that other approaches may impact the presented data in a different manner. This however is left as a piece of future work, which would ideally feature an experimental campaign. Data from specific locations, featuring both wind and wave data at full-scale would be required to perform a fully validated study.

It is now appropriate to examine the simulations in waves featuring a nonuniform flow field, i.e. where an atmospheric boundary layer is modelled. The results, shown jointly in Figure 11 and Figure 12 , suggest that dimensionless velocity magnitudes are affected in a manner that is inverse to that observed for cases where an ABL was omitted. That is, the hierarchy over the $V / V_{\infty}$ scale is flipped: short waves have caused reduced predictions in velocity magnitude relative to long waves. For both locations along the deck length, the $\lambda / L=1.2$ and $\lambda / L=1$ show essentially identical results when an $\mathrm{ABL}$ is included, whereas the $\lambda / \mathrm{L}=0.9$ exhibits the lowest dimensionless velocity values.

It should be noted that in cases where an ABL is modelled, heave and pitch motion amplitudes are relatively smaller than would be the case otherwise. It is therefore expected that the relative difference in dimensionless velocity magnitudes would be smaller. In fact, as pointed out earlier, the 
data for $\lambda / \mathrm{L}=1.2$ and $\lambda / \mathrm{L}=1$ is essentially identical. Another interesting property of Figure 11 and Figure 12 is that in all cases, a strong similarity in predictions is shown between all cases at $y / b=0$. The impact of the presence of the symmetry plane is not fully known, and it is therefore not possible to determine with certainty whether an influence is exacted onto the field in the abovementioned cases. The symmetry plane impacts the solver's ability to account for cross diffusion at $y / b=0$, and is therefore at least in part the reason for the observed trend.

A visual representation of the differences obtained between the cases where an ABL is modelled and a case where it is not modelled is now given. Firstly, the vortices, represented by the Q-criterion (with $\mathrm{Q}=1$ in all cases) is given for the stationary case in Figure 13. The difference in the structure and distribution of the vortices is best seen in this case in the areas occupied by the ship superstructure, which is represented solely via an outline for visualisation purposes. The main difference is that vortices are relatively larger in the case including an ABL. However, of greater interest is the difference between the two cases (with ABL, no ABL) when the ship is responding to waves.

The vortex structures are shown in Figure 14 in the same way as was done in Figure 13 for the stationary case. That is, the ABL cases for each regular wave condition is compared with its uniform flow field condition. It is immediately apparent that vortices are larger and longer when the ABL is included. The penultimate tile of Figure 14 shows the ship having passed through a maximum in motion. Since the case examined is $\lambda / \mathrm{L}=1.2$, the largest motion amplitude are involved, which has caused a clearly identifiable collection of vortices to be shed aft of the ship.

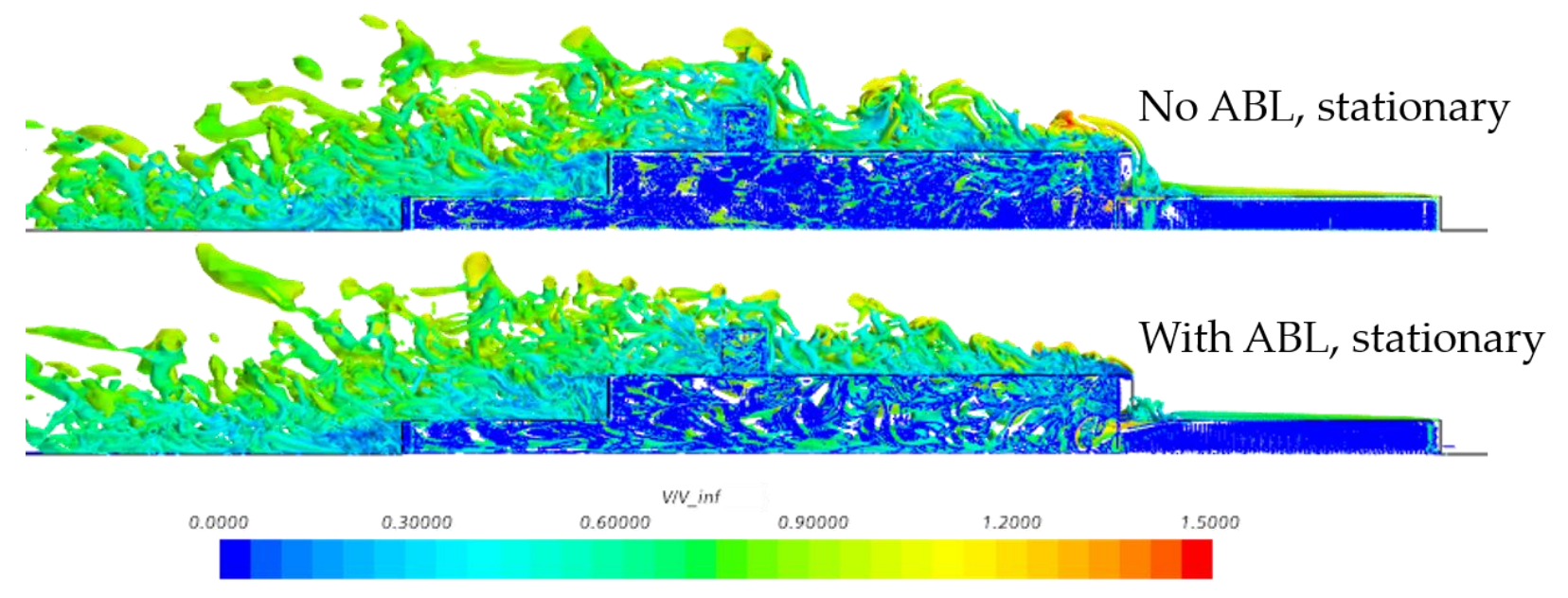

Figure 13. Comparison of the stationary case with and without an $A B L$ for $Q=1$. 
The final item to be discussed and compared in this work is the flow field in terms of dimensionless velocity distribution. This is visualised as smoke, which is limited to the range $0<V / V_{\infty}<0.9$. As is shown in Figure 15, this approach allows the identification of the flow features, such as vortices in terms of the dimensionless velocity, while maintaining the outlines of the hull. Using this method of visualising the results, one can distinguish the relative flow structure and vortices, it is also possible to identify how the vertical distribution of velocity due to the atmospheric boundary layer interacts with different parts of the ship. Particularly interesting is the uplift of lower flow velocity at the hanger.

Similar flow visualisations are done for all cases where the ship is responding to waves. Figure 16, $\lambda / \mathrm{L}=1.2$, i.e. the largest amplitude motions recorded (see Figure 10), allows a visual interpretation of the interactions of the atmospheric boundary layer and ship while heaving and pitching. The previously mentioned uplift of lower velocity flow, closer to the sea surface is transformed into a type of "scooping", induced during motion minima. These push air, characterised by lower flow velocities on top of the hanger periodically, which are visualised in the form of "puffs" of smoke in the present visualisation method. The scooped up flow by the hanger near the bow propagates aft and disrupts the hairpin vortex that would otherwise form at the base of the funnel. Once this portion of the flow reaches the aft section of the ship, it is largely disrupted by the irregular flow in the aft of the hanger, which transforms to a highly chaotic velocity field shed downstream.

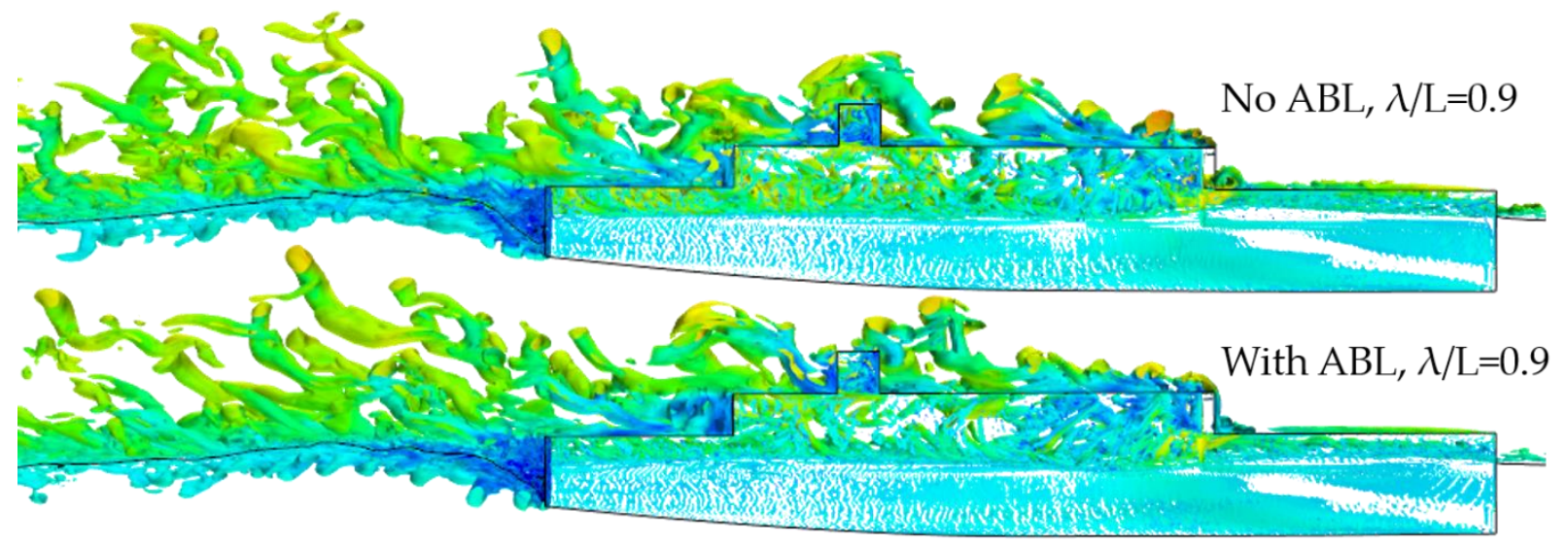



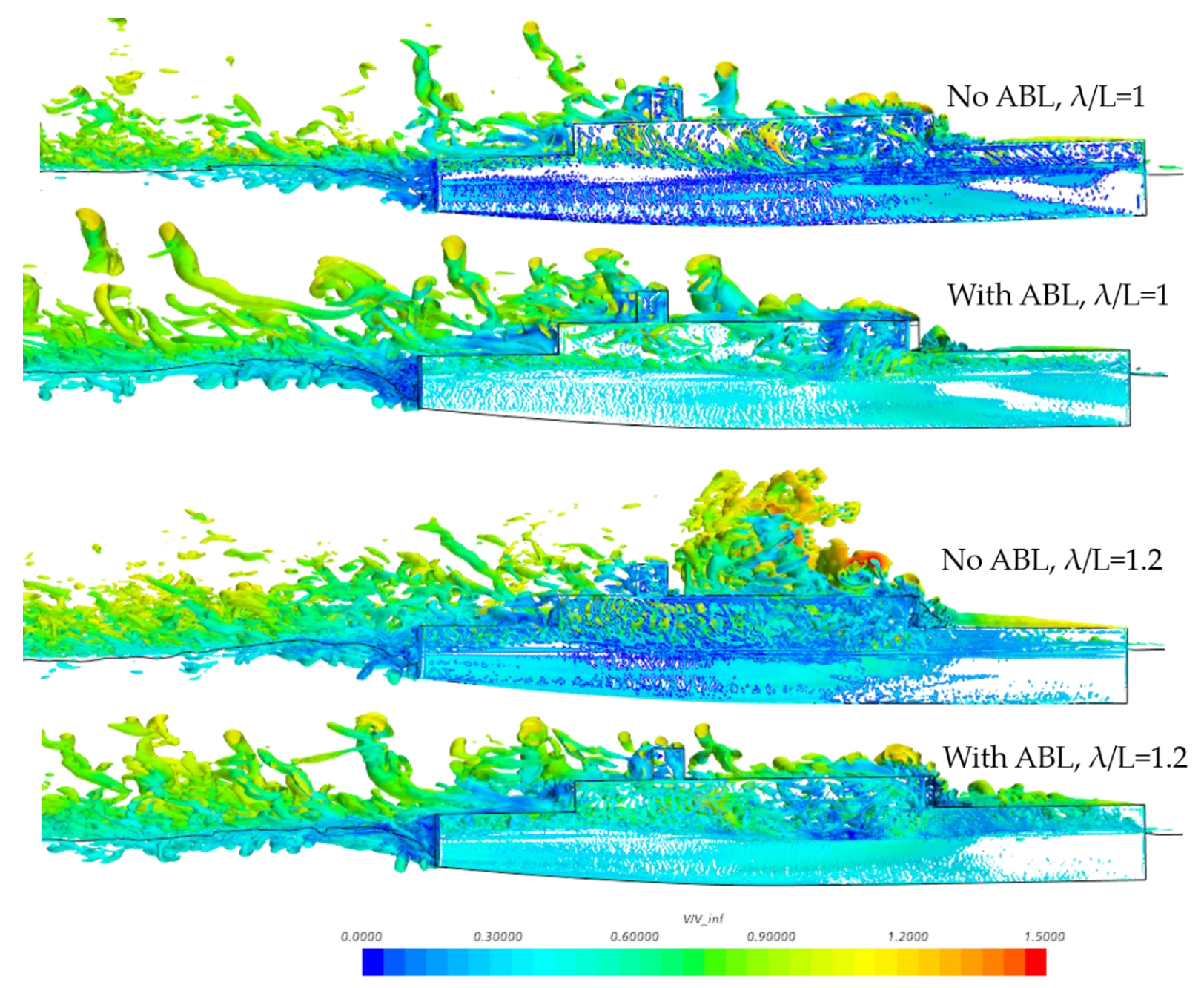

Figure 14 Comparison of the simulations in waves with and without an ABL for $Q=1$. 

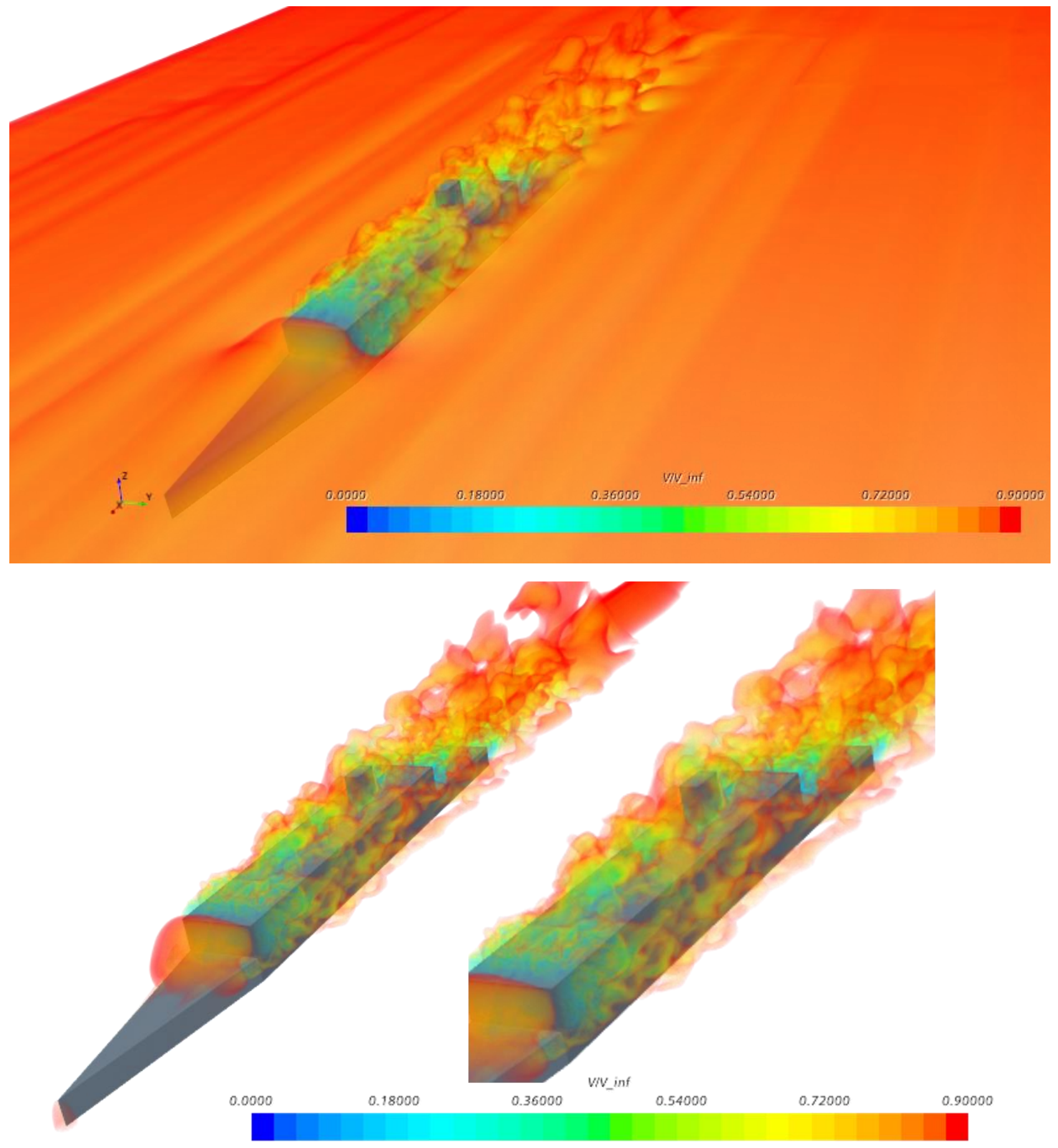

Figure 15. Flow features around the stationary ship. Top: with ABL, bottom: without ABL. 


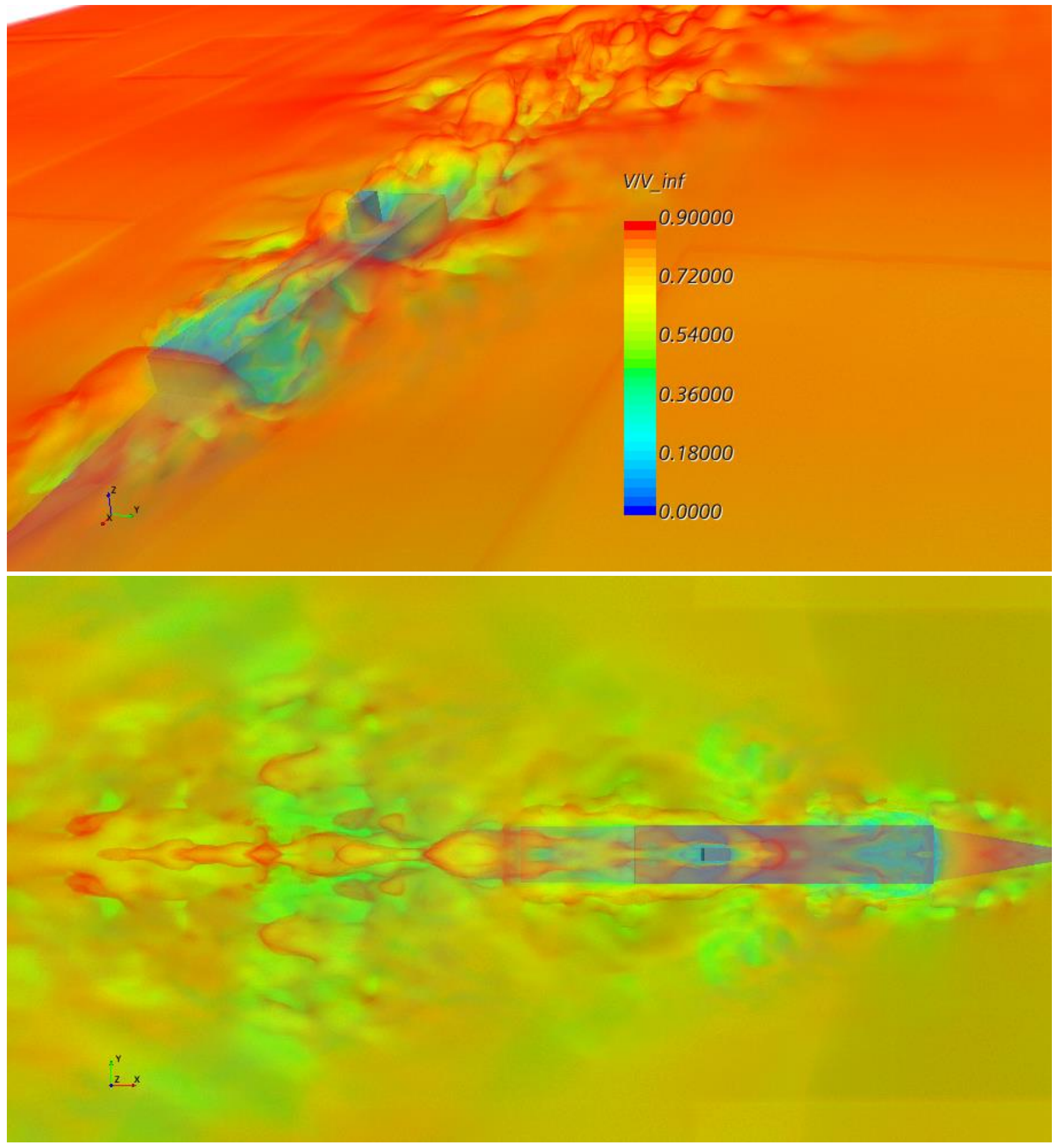

Figure 16. Flow features around the ship for the case $\lambda / \mathrm{L}=1.2$ in the presence of an ABL. 3D view (top tile) and top view (bottom tile); both tiles are scaled with the same colormap. 


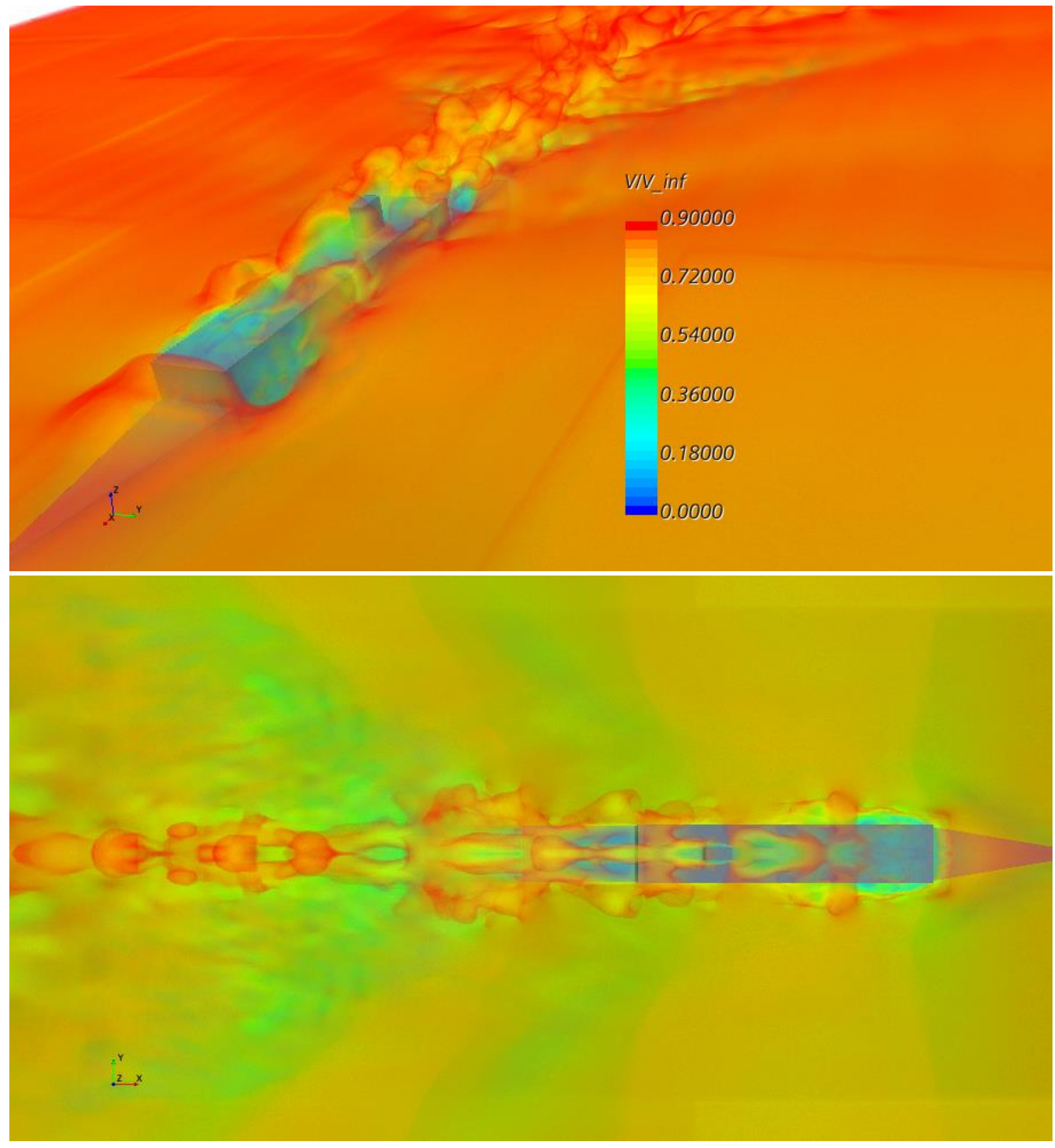

Figure 17. Flow features around the ship for the case $\lambda / L=1$ in the presence of an ABL. 3D view (top tile) and top view (bottom tile); both tiles are scaled with the same colormap. 


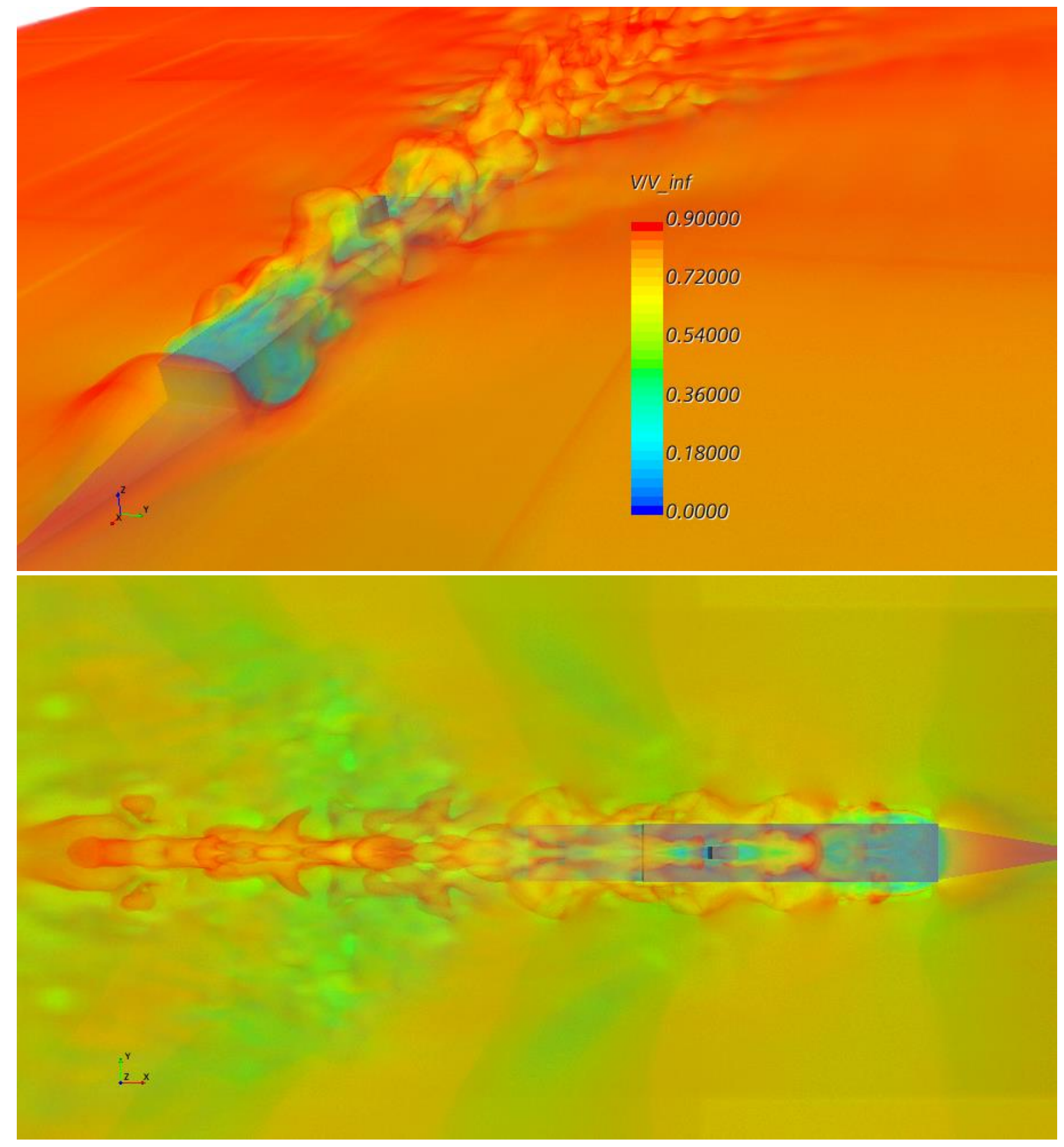

Figure 18. Flow features around the ship for the case $\lambda / L=0.9$ in the presence of an ABL. 3D view (top tile) and top view (bottom tile); both tiles are scaled with the same colormap. 
The discussion for $\lambda / \mathrm{L}=1,0.9$, the features of which are shown in Figure 17 and Figure 18, respectively, is largely similar to that given for $\lambda / \mathrm{L}=1.2$. However, there are some important observations worth noting. Firstly, the difference in wavelength and corresponding change in the structure of the waves, generated by the ship have scarred the velocity field to the extent that even some distance vertically from the water surface, a reduction in the dimensionless velocity persists in areas adjacent to the ship. Interestingly, it does not seem that there are corresponding scars onto the velocity field due to the ambient waves the ship is subjected to in any of the examined cases (consult Figure 16, Figure 17, and Figure 18). This may be deducted by the fact that none of the observed patterns in the flow, corresponding to ambient waves, are in straight lines, normal to the ship centreline.

In other words, the aforementioned patterns conform to the structure of ship-generated waves only and not ambient waves, despite the fact that the latter are significantly smaller and shorter than the former. This is likely connected to the fact that ambient waves are generated in sync with the nonuniform velocity field in the dry parts of the computational domain. Therefore, these form stable structures that propagate through the domain jointly and do not seem to disturb each other palpably. The modification of the flow field due to the generation of ship waves implies that a structure's influence on its surroundings is considerably greater when an atmospheric boundary layer is modelled. A helicopter approaching the ship obliquely will be impacted by the presence of the waves, even when operating at the height of the hangar.

A second observation from Figure 16, Figure 17, and Figure 18 relates to the apparent bubble of reduced velocity magnitude in the forward part of the ship. In each case this is produced as a byproduct of the ship motion, specifically when reaching motion minima. At this point in time, the flow is disrupted in the bow area. This phenomenon is most significant where the motion amplitudes are larger, which is as expected, in the $\lambda / L=1.2$ case. This also interacts with the "puffs" described earlier, both of which exhibit a periodic structure, strictly tied to the period of motion in each case (annotated in for $\lambda / \mathrm{L}=1.2$ in Figure 19). Should the period of motion cause the "puff" incepted at the hangar due to pitch to coincide with the generation of that of the funnel, an amplification effect will be achieved. This is a function of the distance between the aforementioned geometrical features of the ship, the wind speed, period, and amplitude of motion in heave and pitch. When these are misaligned, a helicopter operating downstream of the hanger will feel higher frequency motion due to wind, since there will be two disturbances in each motion period, rather than one amplified disturbance.

The discussion presented above on the visual representation of the flow explains the reduced magnitudes of dimensionless velocity observed when relatively longer waves are modelled, as 
shown in Figure 11 and Figure 12. The combined influence of the structures shed from the hangar and funnel with the significant disturbance in the flow when the ship pitches (the bubble referred to earlier) cause the flow to be modified to a greater extent in long waves, since these cause larger motion amplitudes (see Figure 10). When the ship experiences sufficiently large motion amplitudes, the bubble of disturbed flow can be identified both at the ship hangar where it is incepted, as well as downstream in Figure 19. Here, three circular features of increasing diameter can be identified in the top view representation.

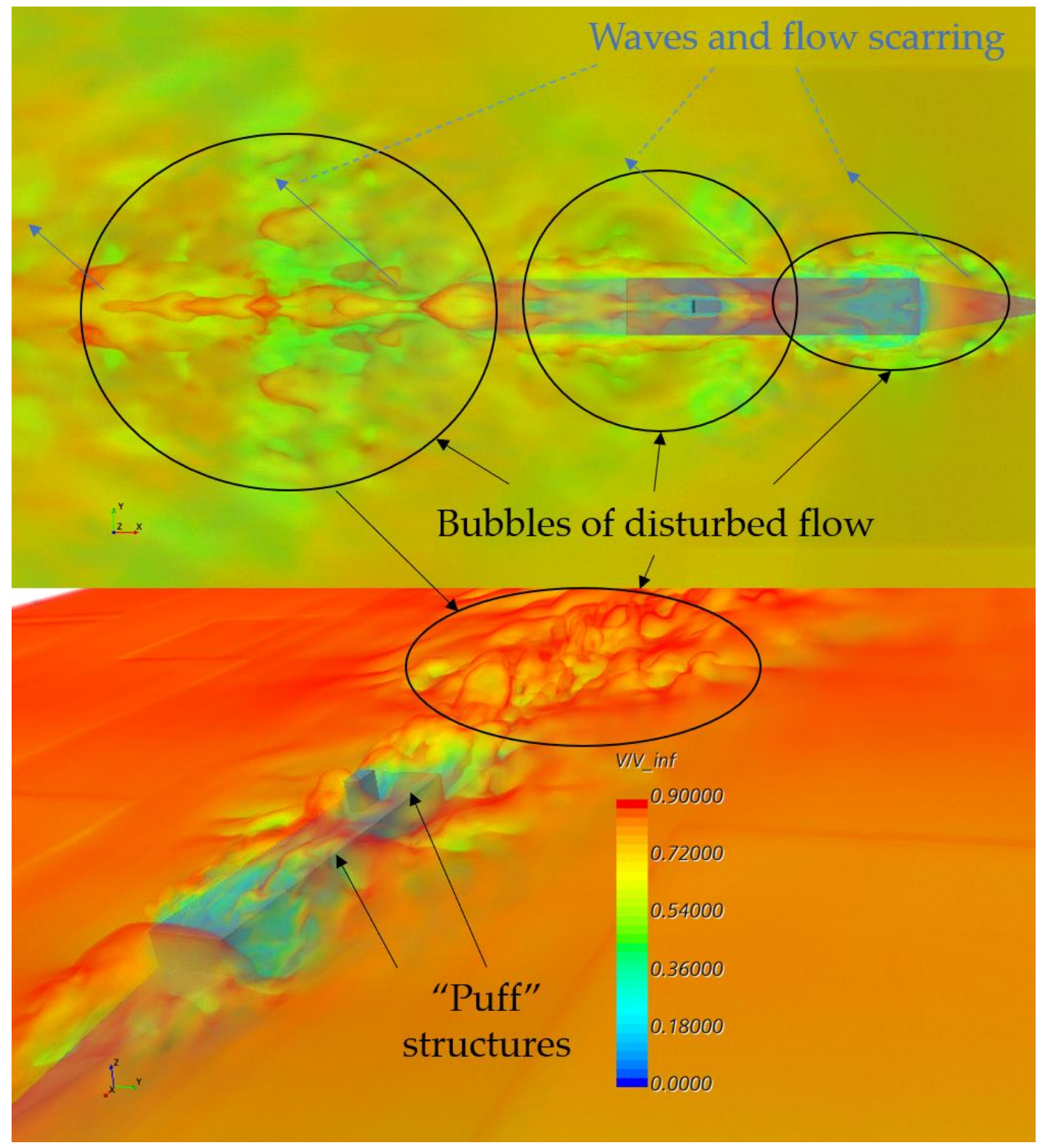

Figure 19. Visual aid in describing the flow structures for the case $\lambda / L=1.2$. 


\subsection{Summary of findings}

The purpose of this section is to provide a concise summary of the key findings. These are supplemented by a more detailed discussion in the following section.

- The ship was simulated in head waves under three difference conditions, $\lambda / L=0.9,1$, and 1.2 and stationary.

- Ships motions were shown to influence the velocity of the aiwake significantly.

- The ABL impacts the velocity data as well as the vertical ship motions.

- Differences between the cases with and without an ABL were found to be in the region of $20.9 \%$ and $22.39 \%$ in the case of heave, and up to $38 \%$ in pitch.

- The presence of an ABL also impacts on the form and period of motions of the ship, causing a shift of $0.022 \times \mathrm{t} / \mathrm{T}_{\mathrm{e}}, 0.077 \times \mathrm{t} / \mathrm{T}_{\mathrm{e}}$, and $0.099 \times \mathrm{t} / \mathrm{T}_{\mathrm{e}}$ for $\lambda / \mathrm{L}=1.2, \lambda / \mathrm{L}=1$, and $\lambda / \mathrm{L}=0.9$, respectively.

\section{Conclusion and recommendations for future work}

This work studied the airwake of a simple frigate shape and the influences exerted on it by the presence of an atmospheric boundary layer and ship motions. The ship was simulated in head waves under three difference conditions, $\lambda / L=0.9,1$, and 1.2 and stationary. All cases were performed with an atmospheric boundary layer and under a uniform inflow condition.

The resulting data revealed that an atmospheric boundary layer interacts with the airwake and ship in a variety of ways. Firstly, the overall velocity magnitude of the flow was reduced by the presence of an ABL, which has been demonstrated in many studies. The contribution of this study to the field is primarily expressed in the finding that an ABL not only reduces the airflow velocity, but also the wave-induced motions of the ship. Differences between the cases with and without an ABL were found to be in the region of $20.9 \%$ and $22.39 \%$ in the case of heave, and up to $38 \%$ in pitch.

The apparent change in motion amplitude was found to vary depending on the wavelength of the regular head waves modelled. In all cases, it was revealed that long waves, or alternatively, higher motion amplitudes, are impacted to a lesser extent, proportionally. Furthermore, the effect of an ABL was noticeable in the encounter period of the ship, where a decrease in the period increased with decreasing $\lambda / L$. In other words, the shape of the time-history was deformed.

The flow field surrounding the ship was found to be significantly impacted by the presence of ship motions. Ship-generated waves cause the flow to be modified in a way not noticeable by the action of the regular ambient waves. This leads to a conclusion that the ship-induced disturbance in the 
wavefield is sufficiently large to cause an observable difference in the wind flow field even at hangar height. Thus, a helicopter approaching the ship obliquely may be influenced by this phenomenon.

Ship motions were shown to interact with the flow in a variety of ways. Firstly, as the ship pitches, it collects air of low velocity from regions closer to the mean water level during a motion minimum, and brings this flow to higher altitudes when reaching a motion maximum. This is then swept downstream, interacting and modifying the flow field in the stern section of the ship. As the ship pitches, particularly when the motion amplitude is large, the ship creates bubbles of disturbed air whose effect is noticeable downstream of the ship. It was found that in some cases, the flow brought from lower altitudes during pitch may interact with an analogously disturbed air by the heave motion. The effect of these two disturbances may be magnified depending on the ship motions, wind speed, and ship geometry.

The present study can be extended in a variety of ways. It would be of considerable interest to validate the flow around the ship in waves. Therefore, an experimental study would be of great interest. The direction and length of the ambient waves and wind relative to the ship track may also be varied, alongside the ship speed inclusion of air compressibility, and geometrical features of the hangar.

\section{Acknowledgements}

Results were obtained using the ARCHIE-WeSt High-Performance Computer (www.archiewest.ac.uk) based at the University of Strathclyde. 


\section{References}

Bentley Systems, 2016. MAXSURF: naval architecture software for all types of vessels.

Boris, J.P., Grinstein, F.F., Oran, E.S., Kolbe, R.L., 1992. New insights into large eddy simulation. Fluid Dyn. Res. 10, 199-228. https://doi.org/10.1016/0169-5983(92)90023-P

Cao, G., Cheng, J., Xiaobo, B., Zhang, Z., Wang, X., 2016. Investigation on the numerical simulation of ship airwake based on DES. Chinese J. Sh. Res. 11, 3-48.

Carrica, P.M., Wilson, R. V., Noack, R.W., Stern, F., 2007. Ship motions using single-phase level set with dynamic overset grids. Comput. Fluids 36, 1415-1433. https://doi.org/10.1016/j.compfluid.2007.01.007

Celik, I.B., Ghia, U., Roache, P.J., Freitas, C.., 2008. Procedure for Estimation and Reporting of Uncertainty Due to Discretization in CFD Applications. J. Fluids Eng. 130, 078001. https://doi.org/10.1115/1.2960953

Cheney, B.T., Zan, J.S., 1999. CFD code validation data and flow topology for the technical cooperation program AER-TP2 simple frigate shape, National Research Council Canada, Institute for Aerospace Research.

Dooley, G., Ezequiel Martin, J., Buchholz, J.H.J., Carrica, P.M., 2020. Ship Airwakes in Waves and Motions and Effects on Helicopter Operation. Comput. Fluids 208, 104627. https://doi.org/10.1016/j.compfluid.2020.104627

Durbin, P.A., Pettersson Reif, B.A., 2011. Statistical theory and modelling for turbulent flow, Second Edi. ed. Wiley.

Ferziger, J.H., Peric, M., 2002. Computational Methods for Fluid Dynamics, Springer. https://doi.org/10.1016/S0898-1221(03)90046-0

Forrest, J., Kaaria, C.H., Owen, I., 2016. Evaluating ship superstructure aerodynamics for maritime helicopter operations through CFD and flight simulation. Aeronaut. J. 120, 1578-1603. 
https://doi.org/10.1017/aer.2016.76

Forrest, J., Owen, I., 2010. An investigation of ship airwakes using Detached-Eddy Simulation. Comput. Fluids 39, 656-673. https://doi.org/10.1016/j.compfluid.2009.11.002

Forrest, J.S., Owen, I., Padfield, G.D., Hodge, S.J., 2012. Ship-helicopter operating limits prediction using piloted flight simulation and time-accurate airwakes. J. Aircr. 49, 1020-1031. https://doi.org/10.2514/1.C031525

Healey, J. V., 1992. Establishing a database for flight in the wakes of structures. J. Aircr. 29, 559-564.

Hirt, C.. W., Nichols, B.. D., 1981. Volume of fluid (VOF) method for the dynamics of free boundaries. J. Comput. Phys. 39, 201-225. https://doi.org/10.1016/0021-9991(81)90145-5

Hurst, D.W., Newman, S.J., 1988. Wind tunnel measurements of ship induced turbulence and the prediction of helicopter rotor blade response, VERTICA.

ITTC, 2017. Quality System Manual Recommended Procedures and Guidelines Procedure Uncertainty Analysis in CFD Verification and Validatio.

ITTC, 2011. Recommended Procedures and Guidelines: Practical Guidelines for Ship CFD. 26th Int. Towing Tank Conf.

Johns, M., 1989. The airwake of a DD-963 class destroyer. Nav. Eng. J. 101, 36-42.

Kääriä, C.H., 2012. Investigating the Impact of Ship Superstructure Aerodynamics on Maritime Helicopter Operations.

Landsberg, A., Boris, J., Sandberg, W., Young, T., 1995. Analysis of the nonlinear coupling effects of a helicopter downwash with an unsteady ship airwake, in: 33rd Aerospace Sciences Meeting and Exhibition. Reno, NV, USA, p. 47.

Liefvendahl, M., Fureby, C., 2017. Grid requirements for LES of ship hydrodynamics in model and full scale. Ocean Eng. 143, 259-268. https://doi.org/10.1016/j.oceaneng.2017.07.055

Liu, J., Longyand, L.N., Modiz, A., 1998. Higher Order Accurate Solutions of Ship Airwake Flow 
Fields Using Parallel Computer, in: AGARD Conference, Amsterdam. p. 13.

Mateer, R., Scott, S., Owen, I., 2018. Superstructure Aerodynamics of the Type 26 Global Combat Ship, in: Proceedings of the International Naval Engineering Conference and Exhibition (INEC).

McRuer, D., 1994. Interdisciplinary interactions and dynamic systems integration. Int. J. Control 59, $3-12$.

Polsky, S., 2006. Progress towards modeling ship/aircraft dynamic interface. Proc. - HPCMP Users Gr. Conf. UGC 163-168. https://doi.org/10.1109/HPCMP-UGC.2006.59

Polsky, S.A., 2003. CFD prediction of airwake flowfields for ships experiencing beam winds, in: 21st AIAA Applied Aerodynamics Conference, June. Orlando, Florida, p. 3657.

Polsky, S.A., 2002. A computational study of unsteady ship airwake, in: 40th AIAA Aerospace Sciences Meeting and Exhibit. American Institute of Aeronautics and Astronautics Inc. https://doi.org/10.2514/6.2002-1022

Polsky, S.A., Bruner, C.W.S., 2002. A computational study of unsteady ship airwake, in: Symposium on Advanced Flow Management: Part A - Vortex Flows and High Angle of Attack for Military Vehicles. Loen, Norway, pp. 25-26. https://doi.org/10.2514/6.2002-1022

Polsky, S.A., Bruner, C.W.S., 2000. Time-accurate computational simulations of an LHA ship airwake, in: 18th Applied Aerodynamics Conference. Denver, CO, USA, p. 4126.

Polsky, S.A., Ghee, T., 2004. Application and verification of sub-grid scale boundary conditions for the prediction of antenna wake flowfields, in: 22nd Applied Aerodynamics Conference and Exhibit, August. Providence, Rhode Island, p. 4841.

Polsky, S.A., Ghee, T.A., 2008. Application and verification of internal boundary conditions for antenna mast wake predictions. J. Wind Eng. Ind. Aerodyn. 96, 817-830. https://doi.org/10.1016/j.jweia.2007.06.010

Polsky, S.A., Imber, R., Czerwiec, R., Ghee, T., 2007. A Computational and Experimental 
Determination of the Air Flow Around the Landing Deck of a US Navy Destroyer, in: 37th AIAA Fluid Dynamics Conference and Exhibit. Miami, Florida, p. 4484.

Reddy, K.R., Toffoletto, R., Jones, K.R.W., 2000. Numerical simulation of ship airwake. Comput. Fluids 29, 451-465. https://doi.org/10.1016/S0045-7930(99)00033-X

Rhoades, M.M., Healey, J. V., 1992. Flight deck aerodynamics of a nonaviation ship. J. Aircr. 29, 619626.

Roache, P.J., 1998. Verification of codes and calculations. AIAA J. 36, 696-702. https://doi.org/10.2514/2.457

Roper, D.M., Owen, I., Padfield, G.D., Hodge, S.J., 2006. Integrating CFD and piloted simulation to quantify ship-helicopter operating limits. Aeronaut. J. 110, 419-428. https://doi.org/10.1017/S0001924000001329

Rosenfeld, N.C., Kimmel, K.R., Sydney, A.J., 2015. Investigation of ship topside modeling practices for wind tunnel experiments. 53rd AIAA Aerosp. Sci. Meet. 1-22. https://doi.org/10.2514/6.2015-0245

Scott, P., White, M.D., Owen, I., 2015. Unsteady CFD Modelling Of Ship Engine Exhaust Gases And Over-Deck Air Temperatures, And The Implications For Maritime Helicopter Operations Personal Aerial Vehicles View project NATO AVT-296 Rotorcraft Flight Simulation Model Fidelity Improvement and Assessment View project SEE PROFILE.

Shukla, S., Sinha, S.S., Singh, S.N., 2019. Ship-helo coupled airwake aerodynamics: A comprehensive review. Prog. Aerosp. Sci. https://doi.org/10.1016/j.paerosci.2019.02.002

Siemens, 2018. Star-CCM+ User Guide version 13.04.

Simonsen, C.D., Otzen, J.F., Joncquez, S., Stern, F., 2013. EFD and CFD for KCS heaving and pitching in regular head waves. J. Mar. Sci. Technol. 18, 435-459. https://doi.org/10.1007/s00773-0130219-0 
Spalart, R., 2001. Young-Person's Guide to Detached-Eddy Simulation Grids.

Strang, W., Tomaro, R., Grismer, M., 1999. The defining methods of Cobalt-60-A parallel, implicit, unstructured Euler/Navier-Stokes flow solver, in: 37th Aerospace Sciences Meeting and Exhibit. Reno, NV, USA, p. 786.

Syms, G.F., 2008. Simulation of simplified-frigate airwakes using a lattice-Boltzmann method. J. Wind Eng. Ind. Aerodyn. 96, 1197-1206. https://doi.org/10.1016/j.jweia.2007.06.040

Tai, T., Carico, D., 1995. Simulation of DD-963 ship airwake by Navier-Stokes method. J. Aircr. 32, 1399-1401.

Tezdogan, T., Demirel, Y.K., Kellett, P., Khorasanchi, M., Incecik, A., Turan, O., 2015. Full-scale unsteady RANS CFD simulations of ship behaviour and performance in head seas due to slow steaming. Ocean Eng. 97, 186-206. https://doi.org/10.1016/j.oceaneng.2015.01.011

Tezdogan, T., Incecik, A., Turan, O., 2016. Full-scale unsteady RANS simulations of vertical ship motions in shallow water. Ocean Eng. 123, 131-145. https://doi.org/10.1016/j.oceaneng.2016.06.047

Woodson, S., Ghee, T., 2005. A computational and experimental determination of the air flow around the landing deck of a us navy destroyer (DDG), in: 23rd AIAA Applied Aerodynamics Conference, June. Toronto, Ontario, Canada, p. 4958.

Zan, S.J., 2005. On aerodynamic modelling and simulation of the dynamic interface. Proc. Inst. Mech. Eng. Part G J. Aerosp. Eng. https://doi.org/10.1243/095441005X30315

Zhang, J., Minelli, G., Rao, A., Basara, B., Bensow, R., Krajnović, S., 2018. Comparison of PANS and LES of the flow past a generic ship. Ocean Eng. 165, 221-236. https://doi.org/10.1016/j.oceaneng.2018.07.023 